\title{
Electrochemical sensors and devices for heavy metals assay in water: the French groups' contribution
}

\section{Luca Pujol 1,2,3, David Evrard ${ }^{1,2}$, Karine Groenen-Serrano ${ }^{1,2}$, Mathilde Freyssinier $^{3}$, Audrey Ruffien-Cizsak ${ }^{3}$ and Pierre Gros ${ }^{1,2 *}$}

1 Université de Toulouse, UPS, INPT, Laboratoire de Génie Chimique, Toulouse, France

${ }^{2}$ CNRS, Laboratoire de Génie Chimique, Toulouse, France

${ }^{3}$ Elta, Blagnac, France

Edited by:

Shusheng Zhang, Qingdao

University of Science and

Technology, Linyi University, China

Reviewed by:

Hajar Sahebalzamani, Islamic Azad

University, Iran

Bankim Sanghavi, University of

Virginia, USA

*Correspondence:

Pierre Gros, Laboratoire de Génie Chimique, UMR UPS/CNRS/INP

5503, Université Toulouse III - Paul

Sabatier, 118, route de Narbonne,

Bâtiment 2R1, 31062 Toulouse

Cedex 9, France

e-mail:gros@chimie.ups-t/se.fr
A great challenge in the area of heavy metal trace detection is the development of electrochemical techniques and devices which are user-friendly, robust, selective, with low detection limits and allowing fast analyses. This review presents the major contribution of the French scientific academic community in the field of electrochemical sensors and electroanalytical methods within the last 20 years. From the well-known polarography to the up-to-date generation of functionalized interfaces, the different strategies dedicated to analytical performances improvement are exposed: stripping voltammetry, solid mercury-free electrode, ion selective sensor, carbon based materials, chemically modified electrodes, nano-structured surfaces. The paper particularly emphasizes their advantages and limits face to the last Water Frame Directive devoted to the Environmental Quality Standards for heavy metals. Recent trends on trace metal speciation as well as on automatic "on line" monitoring devices are also evoked.

Keywords: electrochemical detection, heavy metals, carbon electrode, polarography, mercury-free electrode, chemically modified electrode, ion selective electrode, speciation

\section{INTRODUCTION}

Like many other micropollutants such as drugs or cosmetics and their by-products, pesticides and industrial or household chemicals, heavy metals represent a growing environmental (Callender, 2004; Roy, 2010) and health (Musarrat et al., 2011; Prabhakar et al., 2012) problem. They may be considered as a major source of ecological issues due to their wide overspread in natural media (Mhatre, 1995). Although naturally produced throughout biogeochemical processes, heavy metals occurrence in the environment mainly originates from human activities: air emissions from coal-burning plants, smelters, waste incinerators, process wastes from mining, industrial and urban runoff all participate to their wide spreading (Friedman et al., 1993; Lindqvist, 1995; Nagajyoti et al., 2010). Once released to the environment, these

Abbreviations: ASV, anodic stripping voltammetry; BDD, boron doped diamond; BiFE, bismuth film electrode; CME, chemically modified electrode; CPE, carbon paste electrode; CSV, cathodic stripping voltammetry; CV, cyclic voltammetry; DAPV, differential alternative pulses voltammetry; DLC, diamond like carbon; DME, dropping mercury electrode; DPASV, differential pulse anodic stripping voltammetry; DPV, differential pulse voltammetry; FIA, flow injection analysis; GC, glassy carbon; $\mathrm{HgFE}, \mathrm{Hg}$ film electrode; HMDE, hanging mercury drop electrode; ICP-MS, inductively coupled plasma mass spectroscopy; IEV, ion exchange voltammetry; ISE, ion selective electrode; LOD, limit of detection; LOQ, limit of quantification; LSASV, linear sweep anodic stripping voltammetry; LSSV, linear sweep stripping voltammetry; LSV, linear sweep voltammetry; MSWV, multiple square wave voltammetry; MWCNT, multi-walled carbon nanotube; NPV, normal pulse voltammetry; NPs, nanoparticles; SCP, stripping chronopotentiometry; SMCPE, silica-modified carbon paste electrode; SMDE, static mercury drop electrode; SPE, screen printed electrode; SSCP, stripping chronopotentiometry at scanned deposition potential; SWASV, square wave anodic stripping voltammetry; SWCNT, single-walled carbon nanotube; SWCSV, square wave cathodic stripping voltammetry; SWV, square wave voltammetry; TFME, thin film mercury electrodes; WFD, water frame directive. metals can remain for decades or centuries since they are not biodegradable. Depending on the contamination pathway, they appear at detectable levels in food resources such as vegetables, grains or fruits, and fish or shellfish throughout bioaccumulation all along the trophic chain, thus contaminating the final consumer-human being (Musarrat et al., 2011; Prabhakar et al., 2012). Another contamination way is direct intoxication from domestic environment, for instance lead traces in household plumbing and old house paints.

Once penetrated inside human organism by ingestion (drinking or eating), inhalation or skin contact, heavy metals may be responsible for nausea, vomiting, diarrhea or allergic reactions for short term or low-level exposure (Martin and Griswold, 2009). They can also cause severe diseases in the case of long term or chronic high-level exposure, such as reduced growth and development, cancers, organs or nervous system damages and even death (Prabhakar et al., 2012). There are over 50 elements that are classified as heavy metals, including transition metals, some metalloids, lanthanides and actinides. Among them 17 are considered to be both very toxic and relatively accessible. Lead $(\mathrm{Pb})$, mercury $(\mathrm{Hg})$, arsenic (As), and cadmium $(\mathrm{Cd})$ are generally considered as leader elements in human poisoning even at trace level. The general population is mainly exposed to all these metals from air, drinking water and food, fish being a major source of mercury exposure. Moreover, smokers are highly exposed to cadmium (Järup, 2003). Some other heavy metals, including copper $(\mathrm{Cu})$, zinc $(\mathrm{Zn})$, nickel $(\mathrm{Ni})$, cobalt $(\mathrm{Co})$, selenium $(\mathrm{Se})$, and bismuth (Bi) are known to play a vital role in physiological concentrations but can also be toxic in larger doses. Depending on the metal properties, the toxicity target may be different: kidneys 
Table 1 | Environmental Quality Standards for heavy metals (also called WFD).

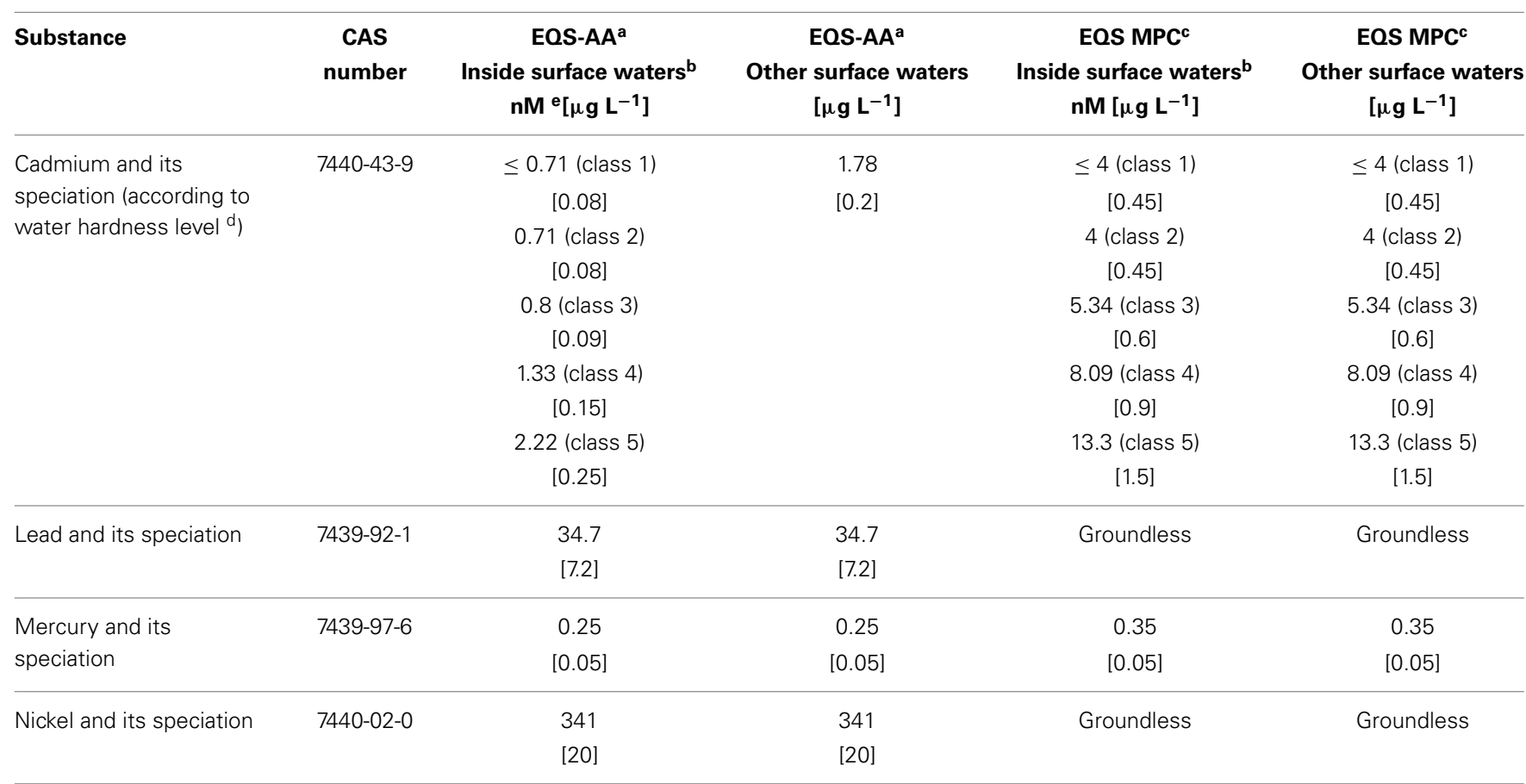

${ }^{a}$ Environmental Quality Standard-annual average.

bInside surface waters include rivers, lakes and also water masses (artificial or seriously modified) related to them.

${ }^{c}$ Environmental Quality Standard-maximal permissible concentration.

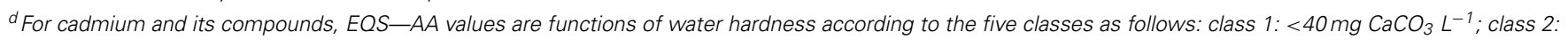
40-50 $\mathrm{mg} \mathrm{CaCO}_{3} \mathrm{~L}^{-1}$; class 3: 50-100 mg CaCO $3 \mathrm{~L}^{-1}$; class 4: 100-200 mg CaCO $\mathrm{L}^{-1}$; class 5: $\geq 200 \mathrm{mg} \mathrm{CaCO}_{3} \mathrm{~L}^{-1}$.

e Molar concentrations have been chosen as reference unit for the sake of comparison facility and regarding to the standards of the WFD (Water Frame Directive), even if this latter uses mass concentrations.

or liver are damaged by $\mathrm{Cu}, \mathrm{Hg}$, and $\mathrm{Pb}$ ions while these latter two also attack central nervous system (Vallee and Ulmer, 1972; Hamilton et al., 1998). Thus, toxicity levels are related to the nature of the metal but also to its biological and biogeochemical roles, both being strongly dependent on its speciation, i.e., the different available physico-chemical forms, namely particulate (size $>1 \mu \mathrm{m})$, colloidal $(1 \mathrm{~nm}-1 \mu \mathrm{m})$ and dissolved $(\leq 1 \mathrm{~nm})$ species. These latter include free metal ions, simple inorganic complexes and complexes bearing anthropogenic and natural organic ligands (Templeton et al., 2000). Hence speciation information on heavy metals of concern appears to be data of particular relevance (Kot and Namiesńik, 2000).

In 2000, a new European directive ("Water Frame Directive," WFD, see Table 1) (European Directive 2000/60/EC) particularly pointed out four heavy metals $(\mathrm{Hg}, \mathrm{Cd}, \mathrm{Pb}, \mathrm{Ni})$ and has established their maximal authorized as well as annual average concentration values in surface waters. As a consequence, environmental monitoring of heavy metals is of critical importance for both ecological assessments and public health preservation. In answer there is an urgent need for in situ, real-time, and highly-sensitive sensors in order to multiply control points dedicated to early warning pollution alert (Suib, 2013).

Heavy metals trace detection is mainly performed using spectroscopic techniques: atomic absorption spectroscopy (Kenawy et al., 2000; Pohl, 2009), inductively coupled plasma mass spectroscopy (ICP-MS) (Caroli et al., 1999; Silva et al., 2009), $\mathrm{X}$-ray fluorescence and neutron activation analysis are the most commonly used. Their main advantages are their versatility since they are suitable for a large panel of elements, their sensitivity and their limit of detection (LOD) in the femtomolar range. However they suffer from several major drawbacks: expensive materials are required and qualified operators are needed to perform the multi-step sample preparation and complex analytical procedures, which are unsuitable for on-site and on time measurements necessary to prevent transient phenomena monitoring. Finally, only total metal concentration can be determined, and speciation data can be reached only by associating supplementary extraction and separation techniques such as chromatography to the spectroscopic detection (Feldmann et al., 2009). These additional steps significantly increase the risk of contamination of the sample and some modifications of the speciation may occur during sample storage or handling.

On the contrary electrochemistry represents an interesting alternative due to its numerous advantages. Electrochemical devices are mostly user-friendly since they require simple procedures. They are also reagentless, low cost, and well-suited for miniaturization and automatic in situ measurements with minimal sample changes. Thus, contamination by reagents or losses by adsorption on containers are drastically decreased. Electrochemical systems also allow quite fast analyses with 
experimental data obtained mostly in real time or in a few minutes. Hence, on-line monitoring of water samples becomes possible, providing dynamic data of relevance for biogeochemical survey. Nevertheless specific developments are still required for such applications, particularly to improve sensitivity, LODs and automation. In this way, a large number of electrochemical techniques with different imposed potential or current modulations have been developed such as differential pulse voltammetry (DPV), square wave voltammetry (SWV) or stripping chronopotentiometry (SCP). Electrochemical sensors also allow high temporal resolution measurements to be obtained when associated to flow injection analysis (FIA) or flow electrochemical analysis cells, thus providing continuous in situ measurements. Another analytical performance of high relevance with respect to heavy metals detection concerns the selectivity. In complex media, the signal of the analytical target often experiences interferences due to the presence of other species (sometimes other heavy metals). To solve this problem, several surface functionalization strategies have been developed for many years to improve sensors selectivity.

Many pioneering researchers coming from several countries have initiated and intensified works dealing with electrochemical techniques for heavy metals detection and assay in natural media: Jaroslav Heyrovsky (Czechoslovakia) (Heyrovsky, 1960), Joseph Wang (USA) (Wang et al., 1995), Richard G. Compton (UK) (Agra-Gutierrez and Compton, 1998), George Luther III (USA) (Luther III and Ferdelman, 1993), Laura Sigg (Switzerland) (Goncalves et al., 1985), Arben Merkoçi (Spain) (Aragay and Merkoçi, 2012), Marco Mascini (Italy) (Voccia et al., 2012), and so on. French contribution to this topic is also noticeable. This is mainly due to the voluntary policy lead since 1998 and the Aarhus protocol in which France contracted to limit its release of $\mathrm{Pb}, \mathrm{Cd}$, and $\mathrm{Hg}$ at a lower level than that recorded in 1990 (Commissariat général au développement durable, 2012). This goal was reached before the protocol came into effect in 2003, but the situation is still worrying: over the 2007-2009 period, 25 heavy metals have been detected in more than $10 \%$ of the analyses performed in French rivers (Commissariat général au développement durable, 2011), whereas the contamination of mussels and oysters, which constitute a good indicator of coastal water pollution, remained stable over the last 3 decades (Commissariat général au développement durable, 2012). This review provides a survey of French groups' contribution to the development of electrochemical sensors and methods aiming at heavy metals detection. The paper particularly emphasizes the multidisciplinary of French scientific investigations through the description of the electrochemical techniques and the evaluation of the corresponding analytical performances.

\section{POLAROGRAPHY}

\section{Classical technique}

Polarography has been certainly the most studied and commonly used electrochemical technique throughout the 20th century since the pioneering work of Heyrovsky in 1922 (Heyrovsky, 1922). This is undoubtedly the consequence of the particular properties of the mercury electrode: continuous renewal of the active surface area, wide cathodic potential window due to the high overpotential corresponding to hydrogen evolution, control of the hydrodynamic conditions by means of mercury drop. These characteristics make polarography a very powerful electrochemical technique for the study of inorganic, organic, organometallic, or biological compounds, not only from a theoretical point of view but also for analytical applications. In this frame the assay of heavy metals has been the subject of numerous papers due to the large inclination of mercury to form amalgams with major metal compounds. For concentrations higher than $10^{-5} \mathrm{M}$ linear sweep voltammetry (LSV) on a dropping mercury electrode (DME) or on a static mercury drop electrode (SMDE) generated at the end of a glass capillary is well-suited. For lower concentrations, the faradic current becomes smaller and the double-layer charging current is not negligible anymore. Pulse techniques, i.e., normal pulse (NPV), differential pulse (DPV) and square wave (SWV) voltammetries have been favored to partially suppress the background current and thus improve the LOD. In the case of trace metals detection these potential pulse programs have been associated with anodic (ASV) or cathodic (CSV) stripping voltammetries on a hanging mercury drop electrode (HMDE) inside which the analyte is pre-concentrated by constant potential electrolysis prior to analysis. The resulting methods, i.e., LSASV, DPASV and SWASV and their combination, allow LODs down to $10^{-12} \mathrm{M}$ to be reached (Bard and Faulkner, 2001). For instance Superville et al. assembled an automatic anodic stripping analysis system with a SMDE to undertake a real-time routine analysis of the dynamic behavior of trace metals $(\mathrm{Zn}, \mathrm{Pb}, \mathrm{Cd})$ in river, pond and seawater (Superville et al., 2011) (see Table 2 for quantitative features). Furthermore a CSV was included to estimate simultaneously the concentration of dissolved oxygen and reduced sulfur species. Magnier et al. perfected a procedure to assay lead and zinc by ASV and copper by CSV in certified reference freshwater and in the French Deûle river, $\mathrm{Cu}$ analysis requiring the complexation with 8-hydroxyquinoline (Magnier et al., 2011).

The need for determination of very low concentrations has favored the development of specific electrochemical techniques with new potential perturbation modes providing high resolution and/or improved sensitivity. In this way Zlatev et al. particularly emphasized the advantages of differential alternative pulses voltammetry (DAPV) on HMDE to analyse mixtures of species exhibiting very close half-wave potentials (like $\mathrm{Pb}^{2+}$ and $\mathrm{Tl}^{+}$ or $\mathrm{Co}^{2+}$ and $\mathrm{Ni}^{2+}$ ) or species couples with high concentration ratios (Zlatev et al., 2006) for which the analysis by DPV is hampered by complete peaks overlapping. DAPV takes advantage of the high resolution power of the second-order voltammetric techniques (as radio-frequency polarography) combined with the high sensitivity and instrumental simplicity of DPV or SWV. DAPV principle is based on the superimposition on the main electrode potential $\mathrm{E}$ of a pair of single successive rectangular pulses characterized by small, equal amplitudes $(<\mathrm{RT} / \mathrm{nF})$ and durations (from 1 to $100 \mathrm{~ms}$ ) but opposite polarities. The overall current recorded at this potential E corresponds to the deviation of the average of the corresponding cathodic and anodic amperometric responses. Thus the resulting current-potential curve exhibits the typical shape of a first-order peak derivative passing three times through zero (for potential ranges corresponding to residual and diffusion-limited currents and for the electrode 


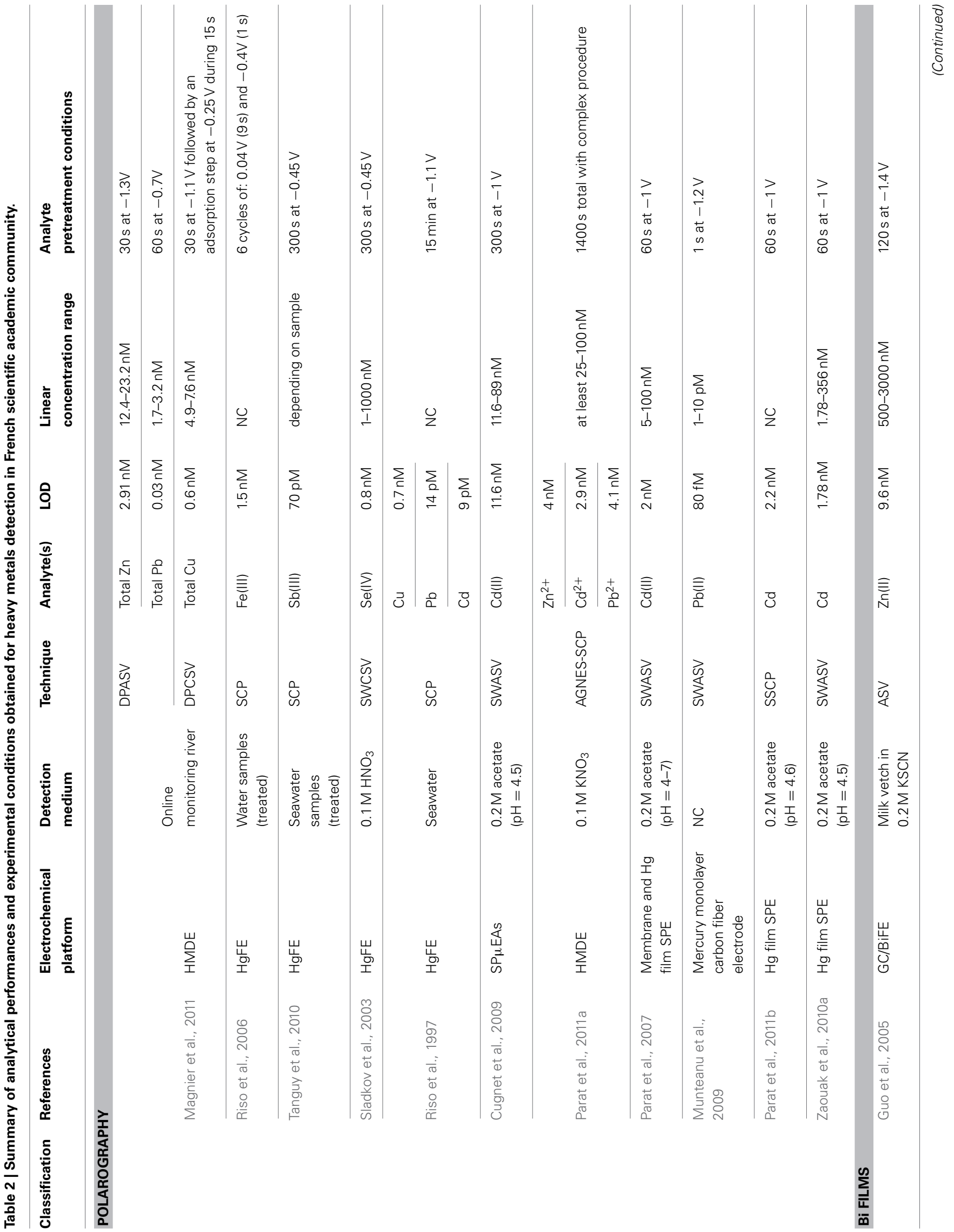




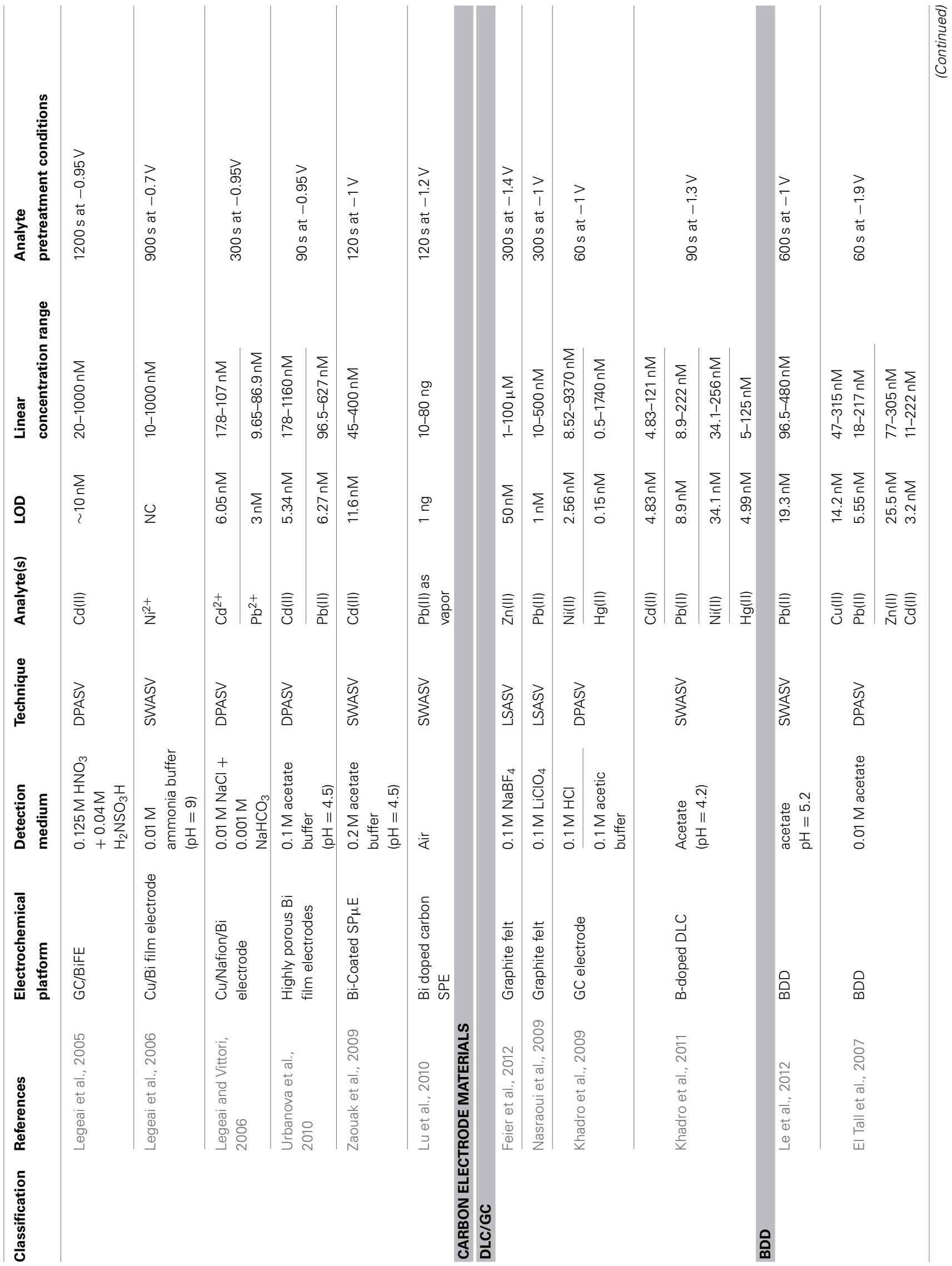




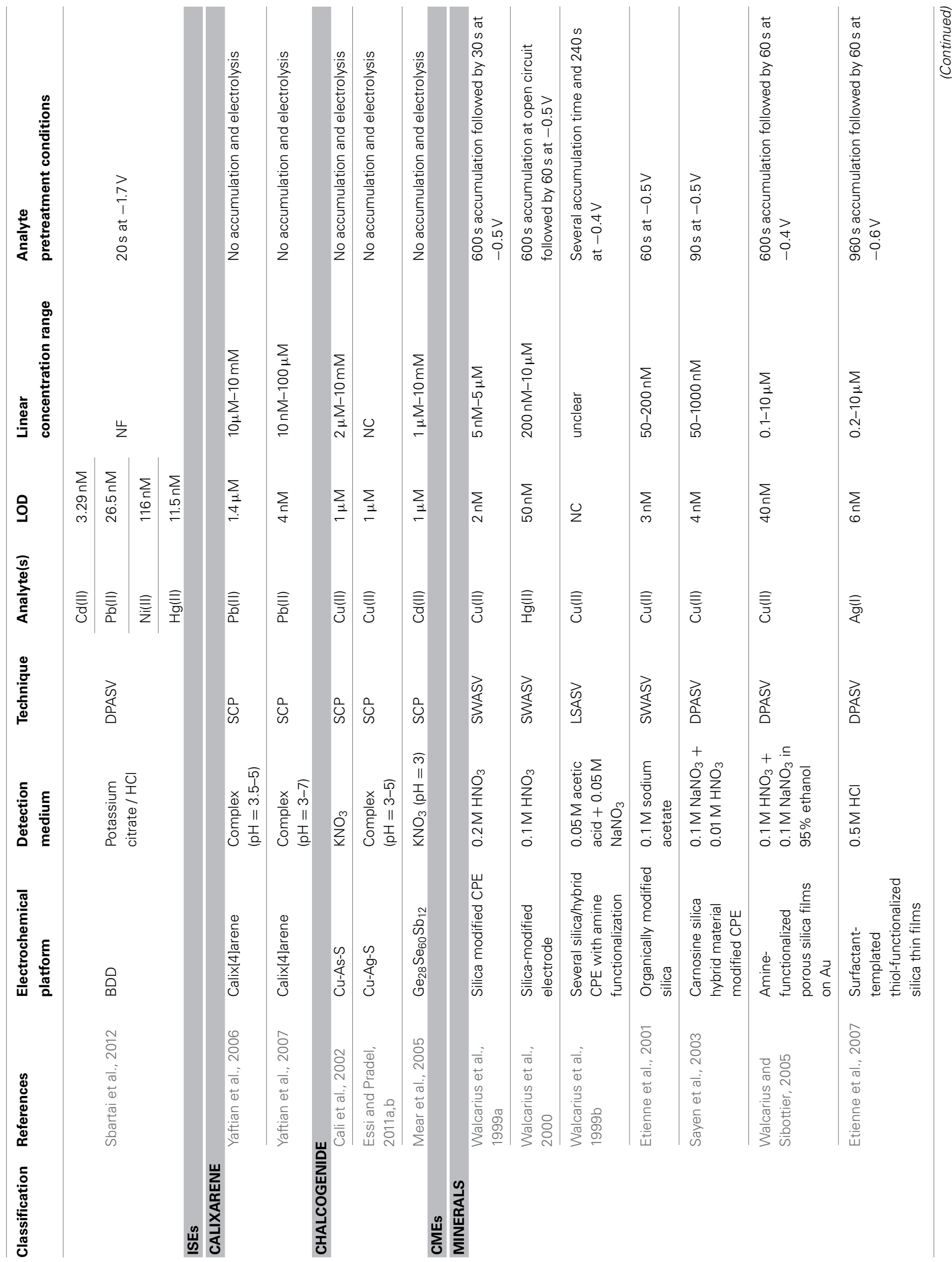




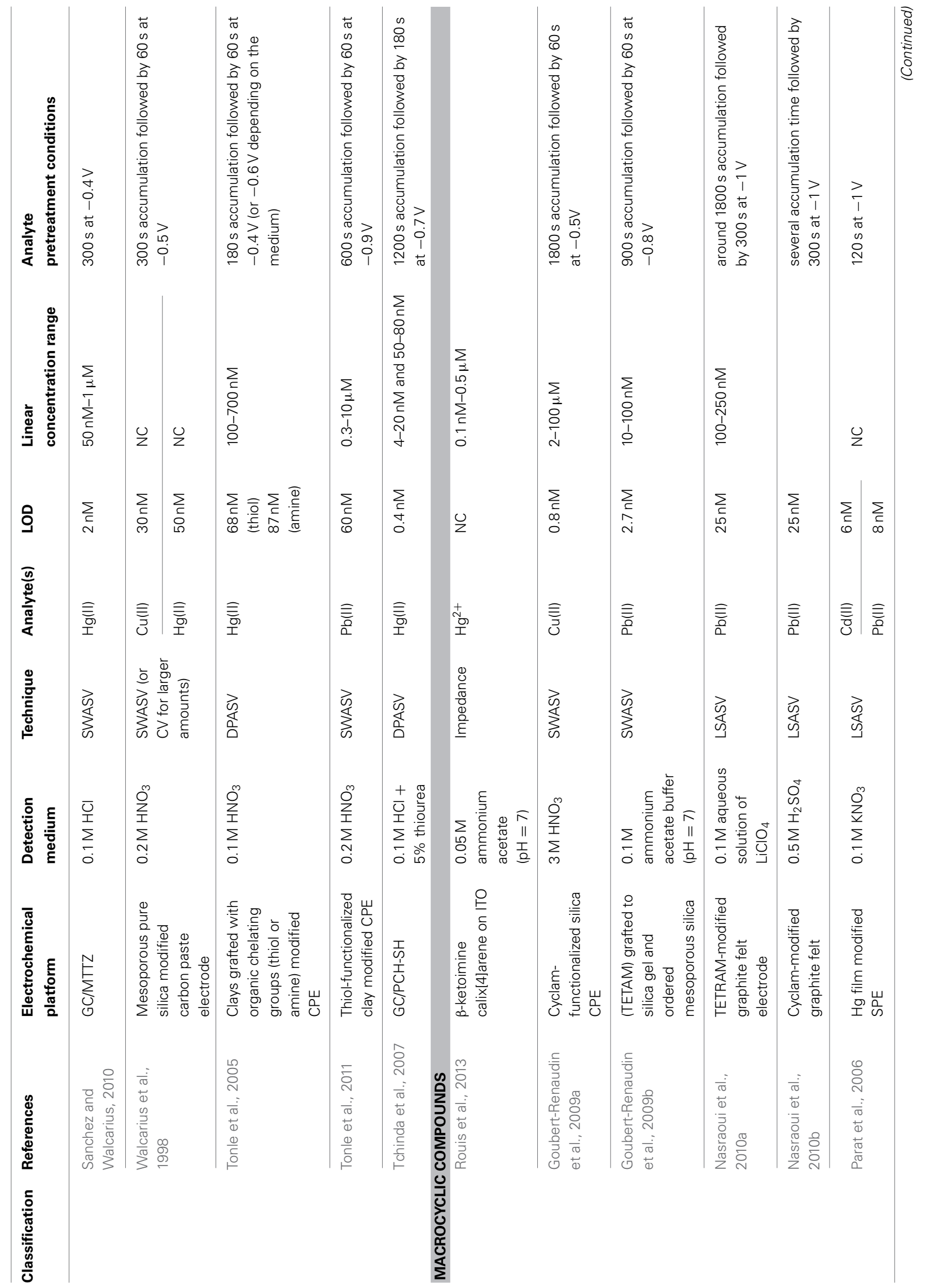




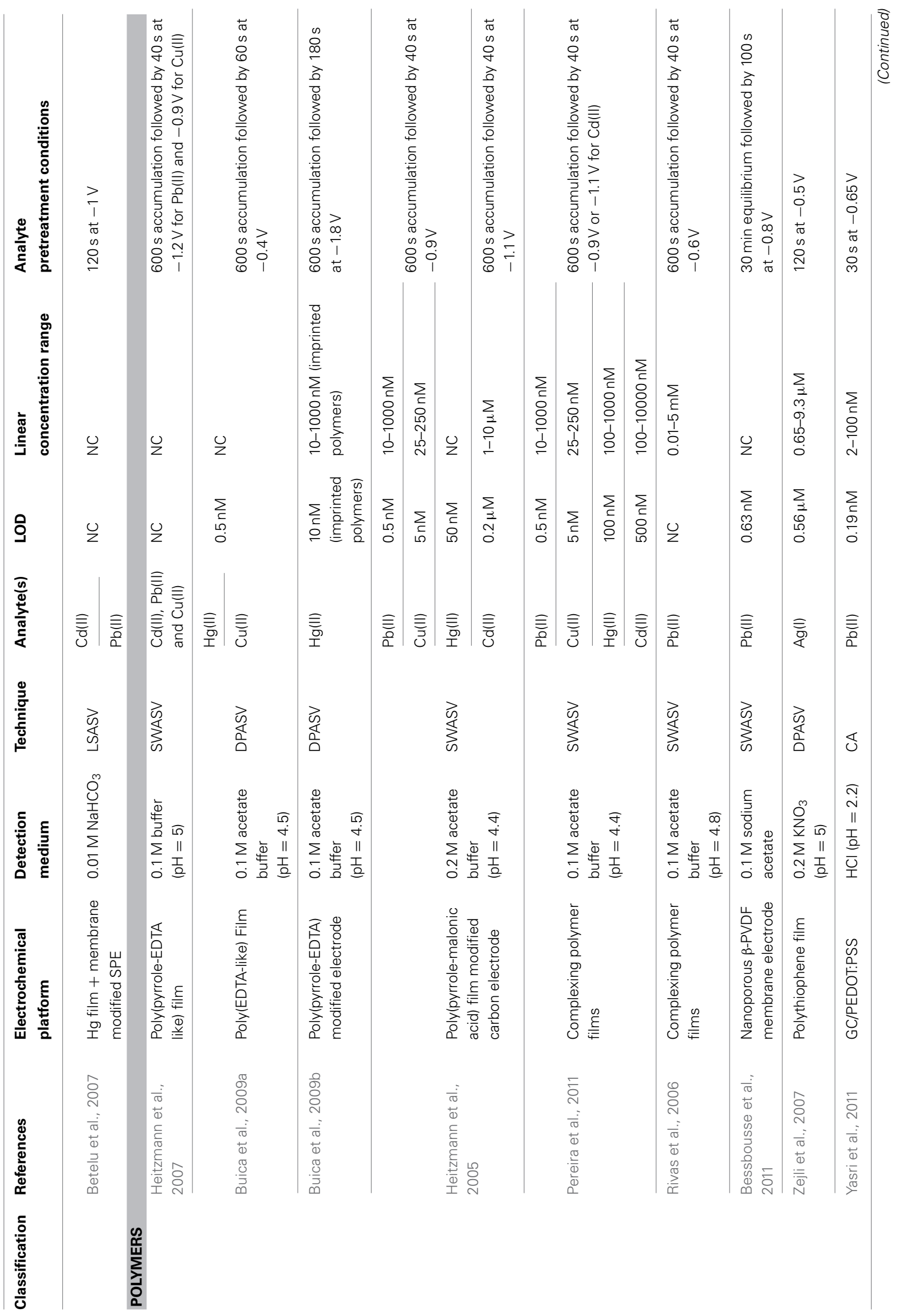




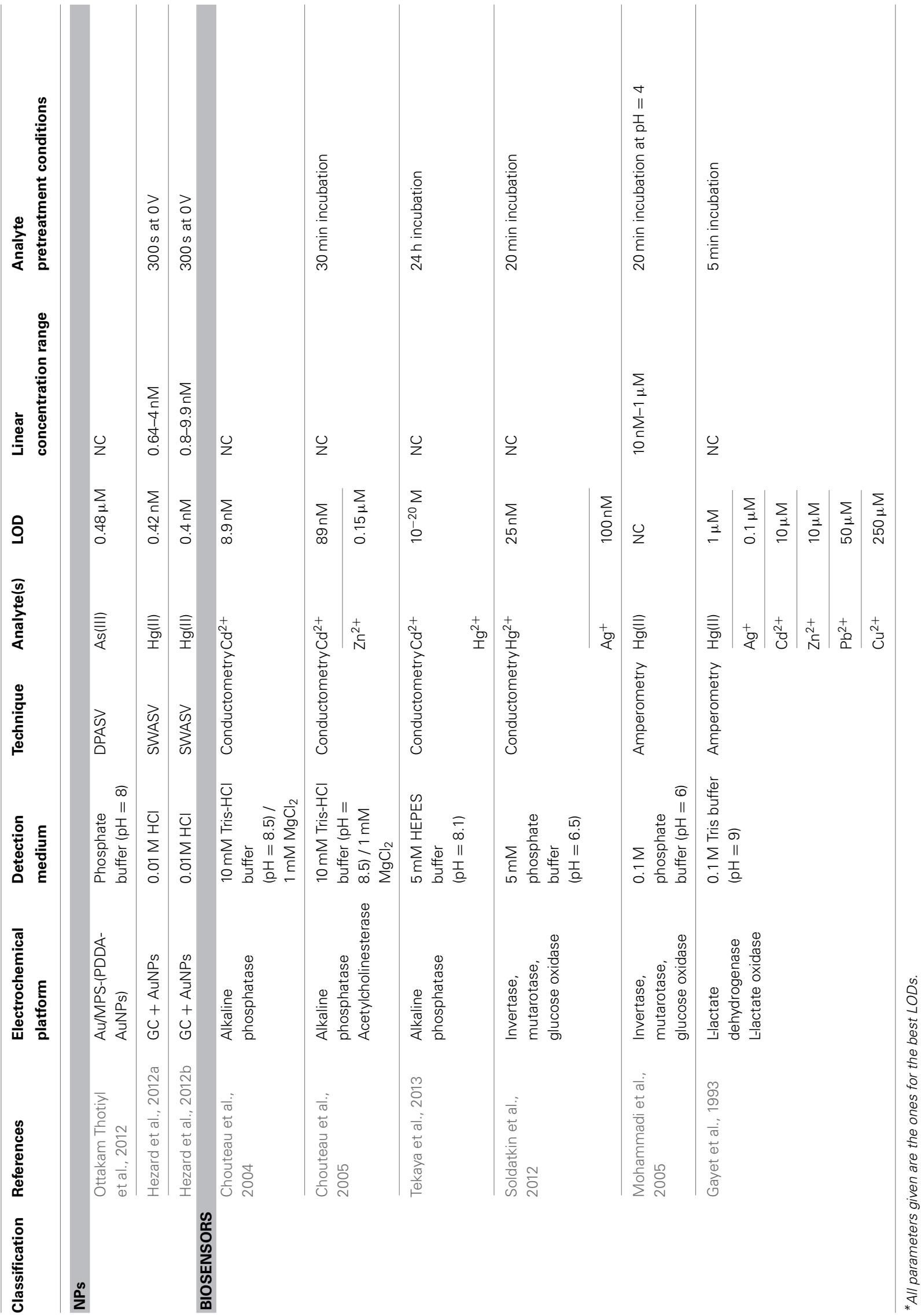


potential equal to the half-wave potential) with peak amplitudes proportional to the electroactive species concentration. The resolution power of DAPV was highlighted through the analysis of a solution containing $\mathrm{Pb}^{2+}, \mathrm{Tl}^{+}, \mathrm{In}^{3+}$, and $\mathrm{Cd}^{2+}$. The sensitivity and the LOD ( $54 \mathrm{nM}$ ) were found to be similar to those obtained using classical DPV but with species having half-wave potentials difference in the range from 28 to $50 \mathrm{mV}$ and concentration ratios from 1:1 up to $80: 1$ without any preliminary preparation of the sample.

\section{Mercury film}

Despite very good analytical performances in terms of sensitivity and stability of the response vs. time, the low vapor pressure and the high toxicity of mercury encouraged extensive researches on polarographic methods involving reduced amounts of mercury. One way consists in thin film mercury electrodes (TFME) electrodeposited on solid state materials like glassy carbon (GC). The group of Riso used SCP with low constant current for the quantification of $\mathrm{Fe}$ (III) in estuarine and coastal filtered waters (Riso et al., 2006). The procedure was proved to be highly sensitive but analysis required several pre-treatment steps, i.e., filtration of the sample and complexation with solochrom violet. They also succeeded in detecting ultra-trace $(70 \mathrm{pM}) \mathrm{Sb}$ (III) in seawater by using the same electrochemical method. The application of a double electrolysis potential during the pre-concentration step allowed the analysis to be independent from the $\mathrm{Cu}$ level (Tanguy et al., 2010).

For the determination of $\mathrm{Se}(\mathrm{IV})$, insufficient reproducibility and sensitivity of $\mathrm{Hg}$ film was observed by Sladkov et al. (2003). This problem was overcome by incorporating $\mathrm{Cu}$ (II) ions during the plating procedure on GC electrode surface. The metallic $\mathrm{Cu}$ dissolved in the $\mathrm{Hg}$ film was found to play an important role in peak current enhancement. A LOD $0.8 \mathrm{nM}$ was reached by SWCSV and the relative standard deviation was $5.2 \%(n=5)$ for $1 \mu \mathrm{M} \mathrm{Se}(\mathrm{IV})$.

A potentiometric stripping method has been proposed by Riso et al. for the simultaneous measurement of $\mathrm{Cu}, \mathrm{Pb}$, and $\mathrm{Cd}$ in ocean waters (Riso et al., 1997). The mercury coating was electrodeposited in situ on a GC rotating electrode at the beginning of each analysis by applying a potential step at $-1.1 \mathrm{~V} / \mathrm{SCE}$ for $10 \mathrm{~min}$. Then an electrolysis-stripping cycle was carried out. Metals concentrations were compared with a reference standard solution containing all three metals. The obtained LODs were $0.7 \mathrm{nM}, 15 \mathrm{pM}$ and $9 \mathrm{pM}$ for $\mathrm{Cu}, \mathrm{Pb}$, and $\mathrm{Cd}$, respectively. However, it has to be noticed that the total duration of the analysis was quite long, about $75 \mathrm{~min}$.

In order to approach solid mercury-free electrodes, Munteanu et al. worked on the electrodeposition of a mercury monolayer by constant potential electrolysis with increasing electrolysis time (Munteanu et al., 2009). An exceptional sensitivity for $\mathrm{Pb}^{2+}$ assay was obtained when the mercury monolayer-on-carbon electrode was used with fast $(v>1 \mathrm{kV} / \mathrm{s})$ ASV. This result was revealed to be due to the ionization of $\mathrm{Pb}$ atoms in the mercury layer, which catalyzes the oxidation of atomic hydrogen adsorbed on the Hg layer. A remarkable LOD of $80 \mathrm{fM}$ was recorded on a cylinder electrode with a $1 \mathrm{~s}$ preconcentration time.

\section{Mercury screen printed electrode (HgSPE)}

Potin-Gautier's group has developed an alternative strategy based on mercury micro arrays screen printed electrodes (SPE). This micro system allowed mass transport of the analytes to be enhanced compared to macro systems. This device was successfully tested for $\mathrm{Cd}^{2+}$ detection in synthetic and river samples, providing a LOD of $11.6 \mathrm{nM}$ using SWASV (Cugnet et al., 2009). More recently SCP was implemented as the second stage of the electrochemical technique "Absence of Gradients and Nernstian Equilibrium Stripping" (AGNES-SCP) for the determination of free metal concentration, namely $\mathrm{Zn}^{2+}, \mathrm{Cd}^{2+}$, and $\mathrm{Pb}^{2+}$, with both an HMDE and a SPE (Parat et al., 2011a). The results showed higher sensitivities and lower LOD and LOQ (in the nanomolar range) with SPE, which was linked to a higher product of mercury volume times the gain (AGNES parameter). Finally, SPE was modified by a microwell for the assay of labile $\mathrm{Cd}^{2+}$, thus reducing the sample volume down to $200 \mu \mathrm{L}$. A LOD of $2 \mathrm{nM}$ was reached using SWASV with only a $60 \mathrm{~s}$ preconcentration step. Unfortunately, the performances of this electrode were $\mathrm{pH}$-dependent out of the $\mathrm{pH}$ range 4-7 (Parat et al., 2007). Nevertheless all these mercury-based techniques are promised to disappear in a few years since no mercury will be authorized from 2015 (European Directive 2008/105/EC).

\section{BISMUTH}

Bismuth film electrode (BiFE) is often considered to be a good alternative to $\mathrm{Hg}$ electrode and has been extensively used for electroanalysis. More "environmentally friendly" and less toxical than $\mathrm{Hg}, \mathrm{Bi}$ is considered to be a safe material, as it is a noncarcinogenic element (except for foetus and embryo) (Svancara et al., 2010). However, in high doses, it presents similar toxicity to other heavy metals apart from these effects are much more reversible. The main advantage of $\mathrm{Bi}$ with respect to trace analysis is its capability to form binary or multi-component alloys with numerous other heavy metals (Svancara et al., 2010). It has also the particularity to be the most diamagnetic metal, thus avoiding conductance problems. Another interest of Bi compared to $\mathrm{Hg}$ is its insensitivity to dissolved oxygen, thus making unnecessary any deaeration step. Most of the time, the Bi film is plated before analysis onto the electrode by potentiostatic reduction of a Bi(III) solution (Wang et al., 2001), although codeposition during trace metal reduction has been also reported (Wang et al., 2000). BiFE performances compare favorably with $\mathrm{Hg}$ electrodes, affording high sensitivity and well-defined stripping signals. For instance, Guo et al. compared the anodic stripping voltammetric response of $\mathrm{HgFE}$ and $\mathrm{BiFE}$ obtained in a $10 \mathrm{mM} \mathrm{Zn}$ (II) solution (Guo et al., 2005). The BiFE presented a well-defined and higher stripping peak compared to HgFE. Its sensitivity was found to be twice higher than that obtained on HgFE. This electrode was then used to detect zinc contained in milk vetch used in traditional Chinese medicine. The response was linear in the range from 0.5 to $3 \mu \mathrm{M}$ and a LOD of $10 \mathrm{nM}$ was reported. Nevertheless, it has to be noticed that the cathodic limit of the potential window is higher than on $\mathrm{Hg}$.

In 2005, Legeai et al. proposed an interesting alternative to the classical Pt or GC substrates by electrodepositing Bi film onto $\mathrm{Cu}$ since the adherence of the film was found to be better in this 
latter case (Legeai et al., 2005). By using DPASV as the detection method, this BiFE exhibited very good performances toward $\mathrm{Cd}^{2+}$ assay in acidified tap water with a linear concentration range between $10^{-8}$ and $10^{-6} \mathrm{M}$. It was also successfully tested for the simultaneous determination of $\mathrm{Cd}^{2+}, \mathrm{Zn}^{2+}$ and $\mathrm{Pb}^{2+}$ ions at $10^{-5} \mathrm{M}$. Good accuracy $(<5 \%)$ was confirmed by comparison of the electrochemical data with those obtained by ICP-MS and mercury-drop electrode on aquatic plant extracts. These results were later generalized to $\mathrm{Ni}^{2+}$ analysis, by using adsorptive stripping voltammetry and dimethylglyoxime as the complexing agent (Legeai et al., 2006). However, BiFEs suffer a major drawback since the formation of Bi hydroxides, which occurs at $\mathrm{pH}$ higher than 4.3, makes the analytical results irreproducible due to film surface changes. To overcome this problem, Legeai et al. used a Nafion-coated Cu substrate for Bi electrodeposition and observed that the Bi particles which were incorporated into the membrane did not experience any hydroxylation reaction (Legeai and Vittori, 2006). This system was successfully used for $\mathrm{Cd}^{2+}$ and $\mathrm{Pb}^{2+}$ detection and exhibited good stability (only 10\% decrease after 23 days).

In a very close approach, Urbanova et al. succeeded in increasing the active surface area of the electrode by depositing Bi onto a polystyrene spheres template (Urbanova et al., 2010). After polystyrene dissolution by toluene washing, the resulting ordered porous film exhibited an original three-dimensional structure which significantly enhanced the analytical performances. These latter were found to be strongly correlated to the Bi film thickness. By using the thickest porous film $(2.2 \mu \mathrm{m}$ thickness $)$ and DPASV method, linear concentration ranges between $178 \mathrm{nM}$ and $1.16 \mu \mathrm{M}$ for $\mathrm{Cd}^{2+}$ ions and between 96.5 and $627 \mathrm{nM}$ for $\mathrm{Pb}^{2+}$ ions were obtained (Figure 1). The LODs were $5.3 \mathrm{nM}$ and $6.3 \mathrm{nM}$ respectively, with a pre-concentration time of $300 \mathrm{~s}$. The standard deviations were lower than $4 \%$ in both cases.

Zaouak et al. reported comparable performances by using a Bi film electrodeposited on carbon screen-printed microband

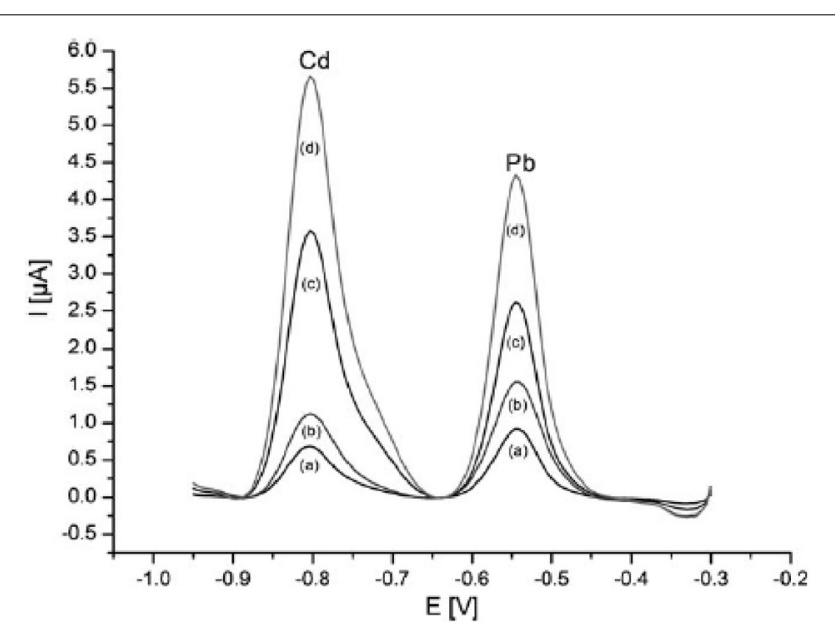

FIGURE 1 | DPASV voltammograms for increasing level of $\mathrm{Cd}$ and $\mathrm{Pb}$ in the 20-130 ppb range on porous Bi film (gold substrate) electrode. Reprinted with permission from Urbanova et al. (2010). Copyright 2010 Wiley-VCH. electrode and SWASV (linear range from 10 to $400 \mathrm{nM}$ and LOD $5.34 \mathrm{nM}$ with $8 \%$ reproducibility and 3\% repeatability in synthetic solution) (Zaouak et al., 2009). This system was successfully tested on non-treated river water sample but exhibited poor stability in this case $(4 \%$ decrease in $10 \mathrm{~min}$ ) due to both $\mathrm{Bi}$ film hydroxylation and biofouling. To overcome this drawback, the authors suggested the renewing of the microband after each measurement.

Finally, the best performances of Bi electrodes were reported by $\mathrm{Lu}$ et al. for trace metal vapors detection (Lu et al., 2010). In this case, Bi powder was simply mixed with carbon ink and the resulting Bi SPE was covered with a $0.1 \mathrm{~mm}$ thickness hydrogel layer by immersion in an agarose solution. This latter acted both as solid electrolyte and preconcentration agent, allowing $\mathrm{Pb}$ vapor concentrations between 48 and $386 \mathrm{pM}$ to be determined with a LOD around $4.8 \mathrm{pM}$. Similar results were obtained with $\mathrm{Zn}$ and $\mathrm{Cd}$.

\section{CARBON ELECTRODE MATERIALS}

Nowadays, a particular attention is paid to more ecofriendly solid electrodes. GC or graphite felts are the easiest carbon based material to obtain (structured with $\mathrm{sp}^{2}$ carbon atoms). Alternatively, Boron doped diamond (BDD) or diamond like carbon (DLC) with $\mathrm{sp}^{3}$ carbon atoms structure are very interesting for their specific properties (McCreery, 2008).

\section{Graphite}

Graphite felts are porous electrodes made of $10 \mu \mathrm{m}$ diameter carbon fibers. They generally present a high specific surface area (around $1200 \mathrm{~cm}^{2} \mathrm{~g}^{-1}$ ) and a high void volume (around 90\%) which enhances hydrodynamics, thus improving the LOD of the resulting sensor. Feier et al. exploited these particular properties to elaborate a flow sensor for $\mathrm{Zn}^{2+}$ trace analysis (Feier et al., 2012). A LOD of $500 \mathrm{nM}$ was reached by LSASV with a $5 \mathrm{~min}$ duration cathodic preconcentration step. Nevertheless the selectivity toward $\mathrm{Zn}^{2+}$ detection was strongly affected by several interfering species such as $\mathrm{Fe}^{3+}, \mathrm{Cu}^{2+}, \mathrm{Co}^{2+}$, and $\mathrm{Ni}^{2+}$. Nasraoui et al. elaborated a $\mathrm{Pb}$ sensor by using a similar flow cell and the same electrochemical method (Nasraoui et al., 2009). A LOD as low as $1 \mathrm{nM}$ was obtained for an overall analysis time of $11 \mathrm{~min}$.

In order to increase the sensitivity, Khadro et al., elaborated a SPE involving active surface carbon deposit ( $1 \mathrm{~mm}$ diameter) for the assay of $\mathrm{Hg}^{2+}$ and $\mathrm{Ni}^{2+}$ (Khadro et al., 2009). Using DPASV as mutual detecting mode, the sensitivity was respectively 10 and 20 times higher than those obtained with a traditional batch electrochemical cell including a three times higher diameter working electrode. Consequently the LODs decreased to 0.15 and $2.56 \mathrm{nM}$ for $\mathrm{Hg}^{2+}$ and $\mathrm{Ni}^{2+}$, respectively. Despite satisfactory performances, the main drawback concerned electrode fouling which obliged the regular regeneration of the surface between analyses and reduced the electrode life-time: Nasraoui et al. observed a decrease about 10 and $20 \%$ of the electrochemical signal after the second and third regeneration, respectively (Nasraoui et al., 2009).

\section{Amorphous nitrogenous carbon thin film (a-CNx)}

a-CNx thin film is a carbon-based material (around $80 \%$ $\mathrm{sp}^{2}$ carbon) including nitrogen atoms. It is synthesized by a 


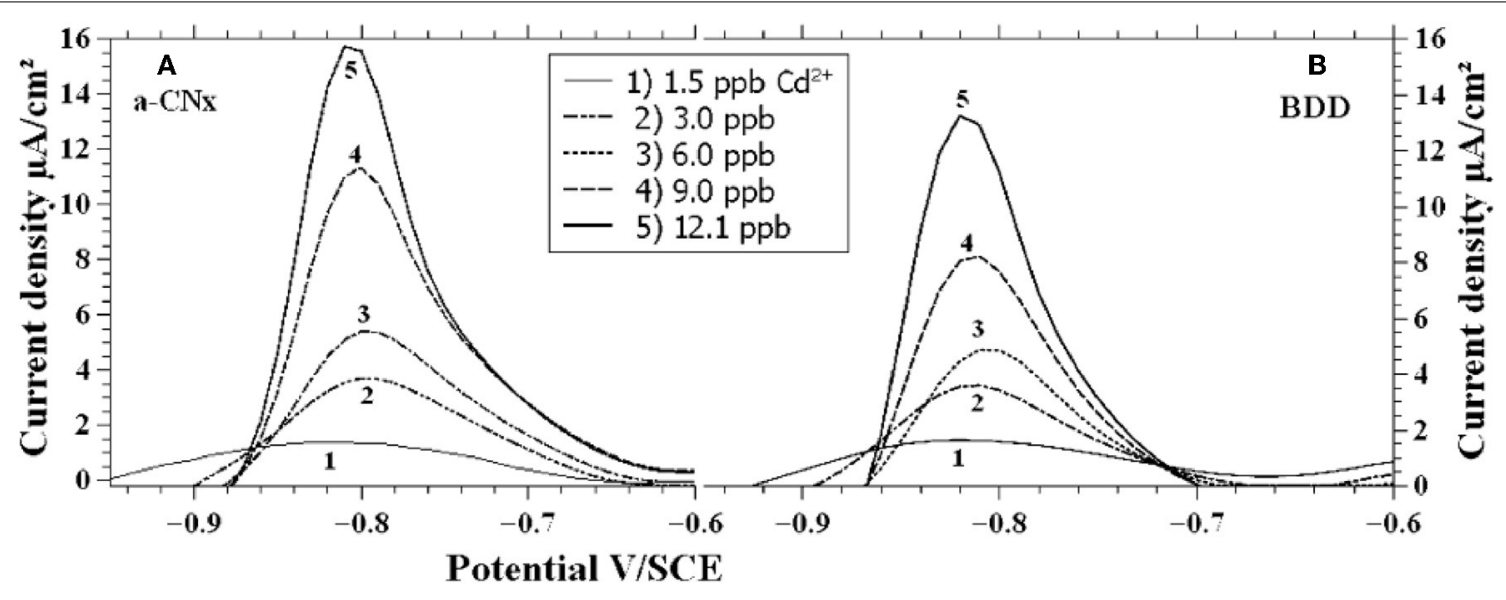

FIGURE 2 | Voltammograms for a-CNx (A) and BDD (B) in solutions containing different Cd $^{2+}$ concentrations. Reprinted with permission from Seck et al. (2012). Copyright 2012 Wiley-VCH.

radio-frequency magnetron sputtering technique. The amount of nitrogen incorporated into the film can be controlled by the composition of the plasma $\left(\mathrm{N}_{2} / \mathrm{Ar}\right.$ ratio) used for the deposition. The main property of a-CNx electrodes concerns their broad electrochemical window, which makes it particularly suitable for electrodetection of many species. This was exploited by Seck et al. for the simultaneous assay of $\mathrm{Cd}^{2+}$ and $\mathrm{Cu}^{2+}$ (Seck et al., 2012) (Figure 2). The presence of $\mathrm{Cu}$ modified the peak current related to $\mathrm{Cd}^{2+}$ as compared to $\mathrm{Cd}^{2+}$ detection in $\mathrm{Cu}$-free solution. Anyway the a-CNx electrode allowed the detection of $2 \mathrm{ppb}$ of $\mathrm{Cd}^{2+}$ with concentration of $\mathrm{Cu}^{2+}$ up to $140 \mathrm{ppb}$.

\section{Diamond like carbon}

Diamond like carbon (DLC) is a carbon-based material containing a mixture of $\mathrm{sp}^{2}$ (graphite) and $\mathrm{sp}^{3}$ (diamond) carbon phases. Several methods have been developed to produce DLC films: plasma enhanced chemical vapor deposition (CVD) techniques, ion beam, filtered cathodic vacuum arcs. DLC exhibits some unique properties, such as high elastic modulus, high mechanical hardness, very low surface roughness and chemical inertness. Khadro et al. used DLC doped with boron to improve its conductivity (Khadro et al., 2011). The resulting electrode was exploited for the simultaneous assay of many heavy metals in water, namely $\mathrm{Cd}^{2+}, \mathrm{Pb}^{2+}, \mathrm{Ni}^{2+}$, and $\mathrm{Hg}^{2+}$, in concentration ranges up to $200 \mathrm{nM}$. LODs of $8.9,4.8,34$, and $5 \mathrm{nM}$ were reached, respectively.

\section{Boron doped diamond}

Boron doped diamond (BDD) is the most recent carbon-based material used for electroanalytical purpose. Diamond films can be deposited using CVD systems involving activation of gases by either microwave plasma or a hot filament. Traditionally electrical conductivity of diamond films is obtained through doping with boron (p-type behavior). The advantages of such material are manifold compared to previous carbon-based ones: BDD has an extremely high chemical stability, presents a wide potential window in aqueous media $\left(-1.35\right.$ to $+2.3 \mathrm{~V} / \mathrm{NHE}$ at $0.1 \mathrm{~mA} \mathrm{~cm} \mathrm{~cm}^{-2}$ in $0.5 \mathrm{M} \mathrm{H}_{2} \mathrm{SO}_{4}$ ) and generates a low background current. Moreover it is extremely resistant to fouling phenomena, thus making its surface state very reproducible with time. Unlike graphite felt, BDD exhibits however lower specific area. In order to increase the sensitivity two major ways have been envisaged. In the one hand, Le et al. associated a BDD electrode with a microelectrodialyser as a preconcentration step (Le et al., 2012). The corresponding device allowed the assay of $\mathrm{Pb}^{2+}$ ions with a linear concentration range between 96 and $490 \mathrm{nM}$ and a LOD of $19 \mathrm{nM}$. The same analytical device was used for the simultaneous detection of $\mathrm{Zn}, \mathrm{Cd}, \mathrm{Pb}$, and $\mathrm{Cu}$ (El Tall et al., 2007). Quantification was possible for the first three heavy metals but the presence of $\mathrm{Cu}$ caused interferences. Compared to GC, BDD electrode exhibited an enhanced sensitivity ( 3 or 5 times) and a longer lifetime in real samples (El Tall et al., 2007). In the other hand, Sbartai et al. developed a new electrochemical microcell micromachined by a femtosecond laser for the simultaneous detection of $\mathrm{Cd}, \mathrm{Ni}, \mathrm{Pb}$, and Hg (Sbartai et al., 2012) (Figure 3). Reduction of the electrode size resulted in mass transport amplification. LODs of 0.4, 6.8, 5.5, and 2.3 $\mathrm{nM}$ were thus obtained, respectively. Quantitative results were recorded for concentrations up to $200 \mathrm{nM}$. These performances are comparable to those obtained on DLC by Khadro et al. for $\mathrm{Pb}^{2+}$ and more accurate for $\mathrm{Hg}^{2+}, \mathrm{Cd}^{2+}$, and $\mathrm{Ni}^{2+}$ (Khadro et al., 2011). However, a non-linear calibration curve for $\mathrm{Hg}$ was obtained in the former paper, which can be explained by the presence of $\mathrm{Cl}^{-}$ions in the electrolyte solution, leading to $\mathrm{Hg}_{2} \mathrm{Cl}_{2}$ formation at the electrode surface.

New carbon materials like a-CNx, DLC or BDD which exhibit high chemical stability and offer a wide potential window hold significant promises for electronalytical applications. Moreover, there is a wealth of opportunities for nanoscale electrochemical devices based on carbon materials. Nevertheless, interceptions between cations go through either the development of specific calibrations or the chemical modification of the electrode.

\section{ION SELECTIVE ELECTRODES}

Ion-selective electrodes (ISEs) are potentiometric sensors that involve a selective membrane which minimizes matrix interferences (Bobacka et al., 2008). The response of these sensors is based on an equilibrium state complexation reaction between the 


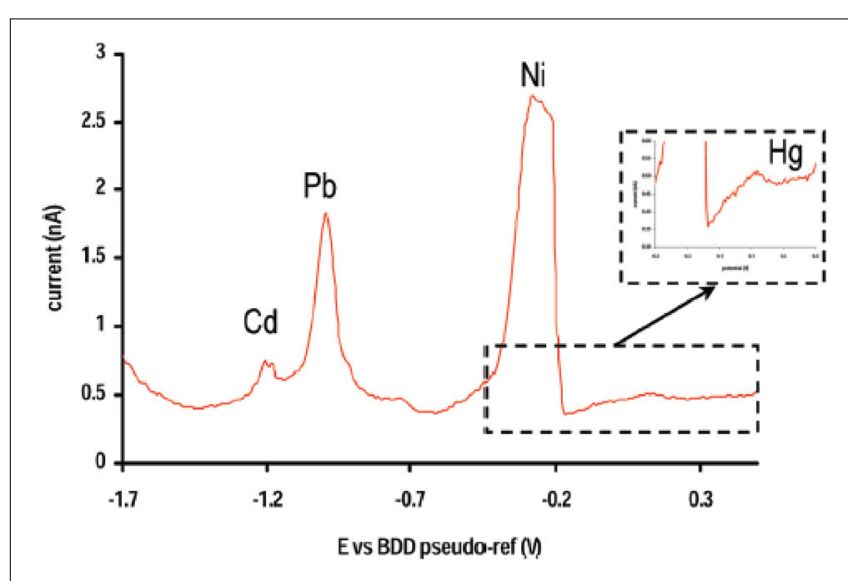

FIGURE 3 | DPASV obtained with a BDD micromachined microcell on a standard solution of $\mathrm{Cd}(20 \mathrm{nM}), \mathrm{Ni}(38 \mathrm{nM}), \mathrm{Pb}(11 \mathrm{nM})$ and $\mathrm{Hg}$

(0.55 nM). Reprinted with permission from Sbartai et al. (2012). Copyright 2012 American Chemical Society.

analyte and the probe with kinetic properties strongly depending on the membrane composition. The potentiometric measurement as well as the nature of the molecular interactions generally allow LODs around $1 \mu \mathrm{M}$ to be reached and a linear concentration range from $10^{-5}$ to $10^{-2} \mathrm{M}$ in a $\mathrm{pH}$ window from 3 to 6 . Innovative changes have been made in recent past years to improve these analytical performances. In this context several functionalized materials have been used, including glass, liquid or polymer membranes. In the latter case an ionophore is generally used as the sensing platform. In this way, Yaftian et al. first synthesized phosphorylated calix[4]arene coated on a graphite electrode for the assay of $\mathrm{Pb}$ traces (Yaftian et al., 2006). This sensor exhibited a particularly quite long lifetime (up to 8 weeks) and a relatively short response time $(17 \mathrm{~s})$. This latter was significantly shortened to $7 \mathrm{~s}$ by using hexahomotrioxacalix[3] arene as the ionophore, due to fast exchange kinetics complexationdecomplexation processes (Yaftian et al., 2007). Furthermore the concentration range covered four decades (between $10^{-8}$ and $\left.10^{-4} \mathrm{M}\right)$. The specificity of this ISE toward $\mathrm{Pb}^{2+}$ was successfully tested in synthetic solution in the presence of 22 interfering species. Nevertheless no measurement was done in real sample water. In both cases, the electrode was also used in potentiometry for the titration of $\mathrm{Pb}^{2+}$ solution using a standard EDTA solution.

Glassy materials represent a good alternative, particularly in micro-sensor fabrication. Beyond the advantages of all solid state devices, vitreous materials are well-suited for the production of homogeneous thin layers which allow potentiometric measurements to be done despite their poor conductivity. Thereby, several types of solid state membranes have been synthesized like the widely used chalcogenide one, in which the conduction over the membrane is provided by halides or metallic ions. Chalcogenide glasses exhibit better chemical durability in acidic media, and in many cases, afford better selectivity and reproducibility than arene ionophores. Several French research teams have investigated such ISEs toward $\mathrm{Cu}(\mathrm{II})$ determination. Cali et al. used chalcogenide glassy-crystalline Cu-As-S alloys (Cali et al., 2002). The resulting sensor exhibited a very short response time (1-3 s) and a LOD close to $10^{-6} \mathrm{M}$ with a linear concentration range between $10^{-6}$ and $10^{-2} \mathrm{M}$. These results are available within a $\mathrm{pH}$ range from 2 to 6 . Similar analytical performances were obtained by Essi et al., with a $\mathrm{Cu}-\mathrm{Ag}-\mathrm{S}$ thin film for the assay of $\mathrm{Cu}$ (II) and $\operatorname{Ag}(\mathrm{I})$ ions (Essi and Pradel, 2011a). They were satisfactorily compared with those obtained by ICP-MS in real samples. Furthermore the specificity of the sensor was not damaged by the simultaneous presence of $\mathrm{Ca}^{2+}, \mathrm{Mg}^{2+}, \mathrm{Pb}^{2+}, \mathrm{Cd}^{2+}$, and $\mathrm{Zn}^{2+}$ (Essi and Pradel, 2011b). Mear et al. investigated a thin film of $\mathrm{Ge}_{28} \mathrm{Se}_{60} \mathrm{Sb}_{12}$ chalcogenide glass including $\mathrm{Cu}$ in order to quantify $\mathrm{Cu}(\mathrm{II})$ ions (Mear et al., 2005). A linear range was found between $10^{-5}$ and $10^{-3} \mathrm{M}$ with a LOD of $3 \mu \mathrm{M}$. The concentration range was enlarged between $10^{-6}$ and $10^{-2} \mathrm{M}$ for $\mathrm{Cd}(\mathrm{II})$ ions assay by coupling the membrane electrode with a pre-concentration module.

\section{CHEMICALLY-MODIFIED ELECTRODES}

From the analytical point of view, the wide and increasing success of chemically modified electrodes (CME) may be explained by the offered possibility to purposely design the surface of conventional electrodes. By combining the intrinsic properties of the modifier and a given electrochemical reaction, CMEs exhibit significantly improved response compared to unmodified electrodes (Murray et al., 1987; Gilmartin and Hart, 1995; Cox et al., 1996). For heavy metals trace detection, the modification plays a critical role especially during the preconcentration step, by favoring selective and enhanced accumulation, thus leading to higher sensitivity and lower LODs (Arrigan, 1994). During the detection step, the modification also often favors the electron transfer kinetics. The modifier may be a mineral such as silica or clay, a polymer, an inorganic or organic compound or a metal nanoparticle based material. Depending on its nature, the modifier is associated to the electrode by adsorption, covalent binding, coating or even dispersion into a conductive matrix.

\section{Minerals}

Minerals such as silica-based materials, clays and zeolithes, are of particular interest for ion exchange voltammetry (IEV) (Wang, 1989). Basically, they act as an ion selective film inside which the analytical target is preconcentrated at open-circuit potential by an exchange process. In a second step, the analyte incorporated within the ion-exchanger film is detected by using an anodic stripping technique (Walcarius, 1998).

In France, the research on silica-modified electrodes with respect to heavy metals assay is mainly represented by the group of Walcarius. In 1997 this group published the first report dealing with silica-modified carbon paste electrode (SMCPE) devoted to electroanalysis, with $\mathrm{Cu}$ (II) as the analytical target (Walcarius and Bessiere, 1997). By using a $10 \mathrm{~min}$ preconcentration step and SWASV, a LOD of $2 \mathrm{nM}$ was reached. This SMCPE exhibited a good reproducibility since up to 30 detection procedures were performed over a period of a week without any noticeable loss of sensitivity. However, this system suffered the classical drawback of CPE, namely a gradual dissolution process. In this particular example, another severe drawback was the necessary use of an 
ammonia medium in order to ensure $\mathrm{Cu}$ (II) accumulation via its interaction with surface silanolate groups. This pioneering work has been later extended to various silica-based materials and the influence of interfering species has been studied (Walcarius et al., 1999a). Clearly, this SMCPE failed at high ionic strength, since important cations concentration resulted in competition for the ion-exchange sites. A very similar study has been reported with $\mathrm{Hg}$ (II) as the analytical target (Walcarius et al., 2000). Using the same procedure and materials, $\mathrm{Hg}$ (II) has been found to suffer no influence of ionic strength and no particular interference with other metallic species, even $\mathrm{Ag}(\mathrm{I})$. This result has been explained taking into account the formation of soluble $\mathrm{Hg}$ (II) hydroxides in the experimental conditions used.

To overcome the drawback of adding a complexing agent in order to ensure metal accumulation, the group of Walcarius has developed several organically modified silica CPEs. Aminopropyl groups (Walcarius et al., 1999b; Etienne et al., 2001) or a carnosine dipeptide (Sayen et al., 2003) have been co-condensed with silane precursors to afford the desired functionalized silica materials. $\mathrm{Cu}$ (II) was detected with similar LODs to those reported in the former study (Walcarius and Bessiere, 1997) without adding anything to the accumulation medium. The aminopropyl-grafted silica CPE was successfully tested for $\mathrm{Cu}$ (II) detection in laboratory tap water (Etienne et al., 2001). Cu(II) suffered important competition from $\mathrm{Co}(\mathrm{II}), \mathrm{Ag}(\mathrm{I})$, and $\mathrm{Hg}(\mathrm{II})$ for the binding sites of the carnosine-modified silica CPE, thus limiting the practical usefulness of this sensor in real media (Sayen et al., 2003).

An interesting alternative to CPE has been proposed later by using silica films coated onto $\mathrm{Au}$ (Walcarius and Sibottier, 2005) or GC (Etienne et al., 2007; Sanchez and Walcarius, 2010) electrodes. Whereas these films have been prepared most of the time by a classical surfactant-templated synthesis (Etienne et al., 2007; Sanchez and Walcarius, 2010) an original electrochemically-induced sol-gel deposition has been also reported (Walcarius and Sibottier, 2005) (Figure 4). All these films were functionalized either by thiol or amine groups. $\mathrm{Cu}^{2+}$ (Walcarius and Sibottier, 2005), $\mathrm{Ag}^{+}$(Etienne et al., 2007) and $\mathrm{Hg}$ (II) (Sanchez and Walcarius, 2010) were the analytical targets, and the LODs obtained were 40,6 , and $24 \mathrm{nM}$ respectively.

From a more general point of view, all these studies on silicabased modifiers proved that the key feature with respect to analytical performances, and particularly sensitivity, is the analyte diffusion inside the porous structure of silica, thus making porosity a more predominant factor than the amount of surface silanol groups (Walcarius et al., 1998). Thus, mesoporous silicabased materials, which exhibit well-defined three-dimensional structures, appear to be much more adapted for heavy metal preconcentration than amorphous ones (Walcarius et al., 2003), whatever they are functionalized (Ganesan and Walcarius, 2008) or not (Walcarius et al., 1998). When functionalized, the amount of organic groups is also of importance, its effect on the analyte preconcentration passing by a maximum, since too much organic groups lead to a decrease in pore size which hampers the accessibility of the binding sites (Etienne et al., 2007; Ganesan and Walcarius, 2008; Sanchez and Walcarius, 2010).

Clays may also be used to perform IEV. These minerals exhibit relatively large specific surface areas and ion-exchange properties associated to an ability to sorb and intercalate many compounds. In a very close approach to what has been reported for silica-based material, their surface may be functionalized by organic groups (Navratilova and Kula, 2003), affording the possibility to tune charge selectivity of clays in IEV (Tonle et al., 2004).

In France, the group of Walcarius explored the potentialities of clays functionalized by organic groups and mixed with CPE toward $\mathrm{Hg}$ (II) (Tonle et al., 2003, 2005) and $\mathrm{Pb}$ (II) (Tonle et al., 2011) determination. With respect to $\mathrm{Hg}(\mathrm{II})$, the comparison of thiol-functionalized vs. amine-functionalized clays showed that the former one exhibited a better LOD (68 and $87 \mathrm{nM}$,
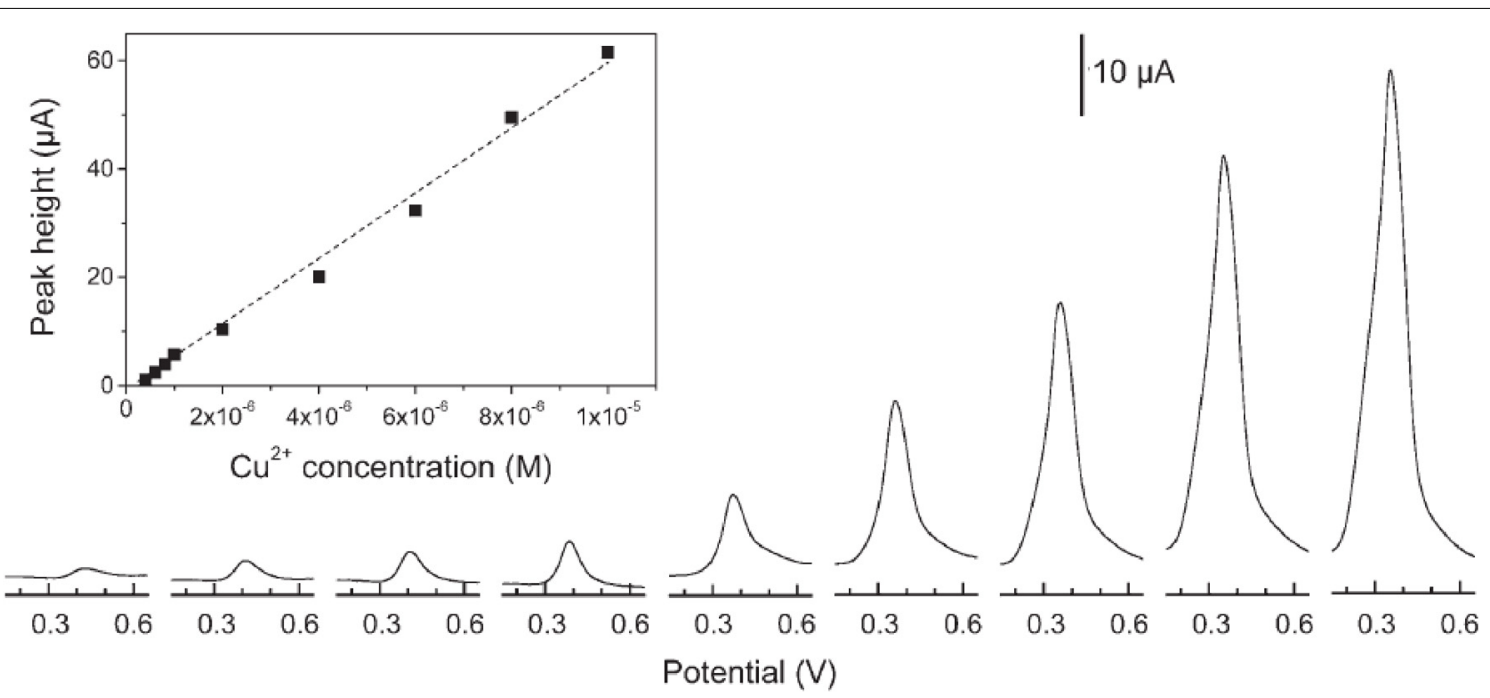

FIGURE 4 | Typical DPASV and calibration (inset panel) curves obtained for $\mathrm{Cu}^{2+}$ using a $10 \%$ amine functionalized silica film deposited on gold. Reprinted with permission from Walcarius and Sibottier (2005). Copyright 2005 Wiley-VCH. 
respectively, using DPASV with 10 min accumulation), in accordance with the greater affinity of $\mathrm{Hg}$ for sulfur groups (Tonle et al., 2005). Thiol-functionalized clays have been also coated as thin films onto GC (Tchinda et al., 2007, 2009). The LOD has been greatly improved since a $6 \mathrm{nM}$ value was reached using DPASV with only $3 \mathrm{~min}$ accumulation, the linear range being from 50 to $800 \mathrm{nM}$ (Tchinda et al., 2007). It has to be noticed that increasing the accumulation time allowed another linear range to be observed from 4 to $20 \mathrm{nM}$ together with a remarkable LOD of $0.5 \mathrm{nM}$ (Tchinda et al., 2007).

\section{Macrocyclic compounds}

Macrocyclic compounds have received much attention in the last two decades due to their particular three-dimensional shape which provides a suitable cavity for selective complexation of heavy metals (Kolthoff, 1979). French groups particularly focused their research on cyclams (Goubert-Renaudin et al., 2009a,b; Nasraoui et al., 2010a,b), crown-ethers (Parat et al., 2006; Betelu et al., 2007) and calixarenes (Dernane et al., 2013; Rouis et al., 2013).

With respect to these latter compounds, Dernane et al. proposed to detect $\mathrm{Cd}^{2+}$ thanks to a $p$-tert-butylcalix[8] arene membrane deposited onto Au electrode (Dernane et al., 2013). In this work the metal cation coordination was favored by the presence of the four ketone groups on the calixarene, thus allowing a $0.1 \mu \mathrm{M}$ LOD to be reached. However the results seemed a little bit cautious since detection was performed simply by CV without further preconcentration step. Moreover, the variation of peak current density as a function of the logarithm of metal concentration was proposed as a calibration plot, which makes non-sense with respect to classical equations of $\mathrm{CV}$.

Rouis et al. have built an impedancemetric sensor dedicated to $\mathrm{Hg}^{2+}$ detection by immobilizing a $\beta$-ketoimine calix[4] arene derivative in a conducting poly ( $p$-phenylene vinylene) membrane deposited onto indium-tin oxide (ITO) electrodes (Rouis et al., 2013). The main originality of this work was the study of light excitation effect of the $\beta$-ketoimine calix[4]arene while optimizing detection parameters. Charge transfer processes at the electrode/electrolyte interface were found to be improved under light excitation, thus providing an enhancement of the sensitivity toward $\mathrm{Hg}^{2+}$. The best results were obtained under blue light emission, providing a charge transfer resistance $R_{c t}=4.47 \mathrm{k} \Omega$ and a linear range from $0.1 \mathrm{nM}$ to $0.5 \mu \mathrm{M}$.

Parat et al. reported the use of a thin-film mercury-coated screen-printed carbon electrode covered by a crown-ether based membrane for the determination of $\mathrm{Cd}$ and $\mathrm{Pb}$ (Parat et al., 2006). The crown-ether membrane aimed at protecting the active surface from interferences during the analysis. The size of crownethers cavity has been proved to impact the performances of the electrode. The best results have been obtained for the smallest crown-ether, because its cavity size fitted well to metal ions radii, although $\mathrm{Pb}$ was a bit favored. LODs of $6 \mathrm{nM}$ and $8 \mathrm{nM}$ for $\mathrm{Cd}^{2+}$ and $\mathrm{Pb}^{2+}$, respectively, have been reached by using LSASV with 2 min preconcentration. Tests were successfully conducted on river water and soil solution extracts. This system was then applied in a later work to the semi-continuous monitoring of $\mathrm{Cd}$ and $\mathrm{Pb}$ in tap water by FIA and afforded reproducible results for 42 h (Betelu et al., 2007) (Figure 5).

Goubert-Renaudin et al. have developed a new family of functionalized cyclams they grafted onto silica materials and mixed to CPE (Goubert-Renaudin et al., 2009a,b). In the first work dedicated to $\mathrm{Cu}$ (II) detection, the functionalization aimed at stabilizing cyclams on silica in order to improve the sensor lifetime. However, increasing the number of functionalizations per cyclam lead to an increase in cycle rigidity, which has been correlated to lower performances with respect to $\mathrm{Cu}$ (II) uptake (Goubert-Renaudin et al., 2009a). The modified CPE afforded good stability, with a 7\% relative standard deviation for 45 measurements and was successfully tested on tap water. In a second work, dealing with $\mathrm{Pb}(\mathrm{II})$ determination, the aim of the functionalization was to improve the analyte preconcentration step by favoring complexation (Goubert-Renaudin et al., 2009b). Thus, the inverse trend was observed, i.e., the more functionalized the cyclam, the better the performances. The best system allowed LODs down to $2.7 \mathrm{nM}$ to be reached. Among potential interfering species, only $\mathrm{Hg}(\mathrm{II}), \mathrm{Cd}(\mathrm{II})$, and $\mathrm{Cu}(\mathrm{II})$ gave rise to significant loss of signal, mainly because of competition for the binding sites. The group of Geneste also used such kind of cyclams to functionalize graphite felt electrodes (Nasraoui et al., 2010a,b). Accumulation of $\mathrm{Pb}(\mathrm{II})$ at open-circuit potential by flowing the
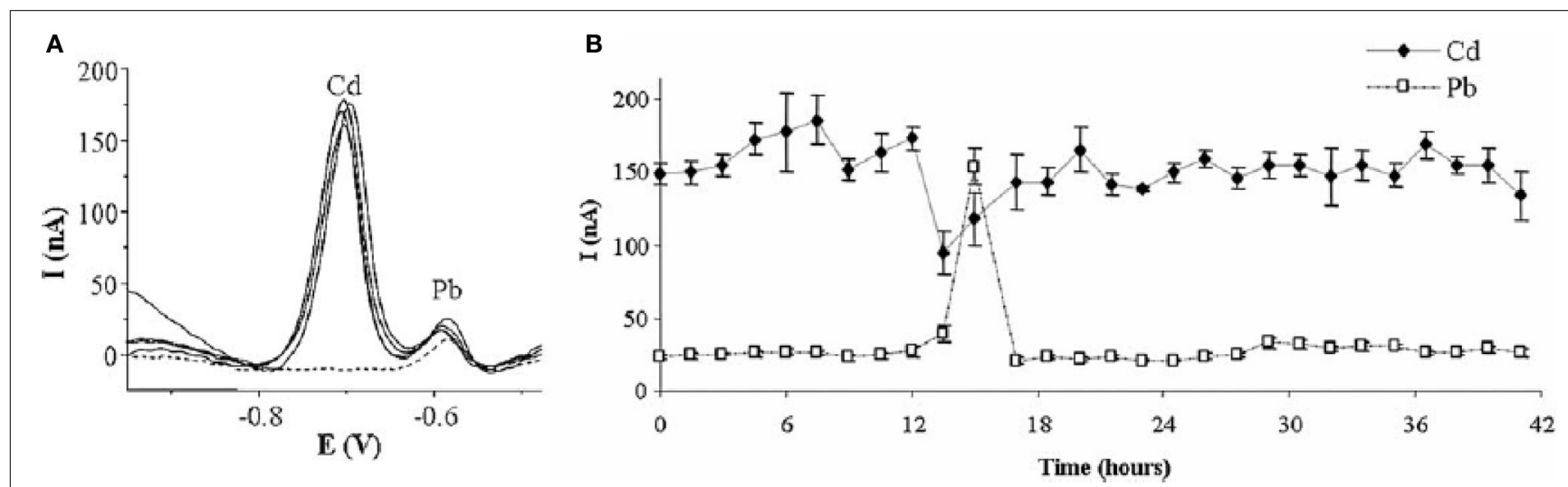

FIGURE 5 | (A) SW Voltammogram recorded every $12 \mathrm{~h}$ for $42 \mathrm{~h}$ analysis by semicontinuous flow injection of tap water doped with Cd (B) Variation of Cd and $\mathrm{Pb}$ peak currents over the $42 \mathrm{~h}$. Reprinted with permission from Betelu et al. (2007). Copyright $2007 \mathrm{Wiley-VCH}$. 
aqueous solution to analyze, followed by LSASV allowed a $25 \mathrm{nM}$ LOD to be reached. However, this system exhibited relatively poor stability since a $20 \%$ decrease of the response was reported after regeneration.

\section{Polymers}

Electroactive surface modification by means of polymer deposition or electrodeposition represents a broad research field, leading to numerous papers every year. With respect to trace metals analysis, polymer films allow the immobilization on the electrode of a large number of ligands which may complex metal ions to be accumulated (Trojanowicz, 2003; El Kaoutit, 2012; Li et al., 2012). The polymers used for surface modification may be natural or prepared purposely by chemical synthesis. However, with respect to French groups' research activities, no work was found dealing with natural polymers dedicated to trace metal detection. The only papers found in the literature were about polysaccharides (Crini, 2005) and chitosan (Vieira et al., 2011) and concerned heavy metals removal.

Concerning chemically synthesized polymers, the group of Moutet has developed two different groups of substituted polypyrrole derivatives for trace metal determination. The first one is based on "poly(pyrrole-EDTA like)" and takes advantage of the well-known complexing properties of EDTA to improve metal preconcentration (Heitzmann et al., 2007; Buica et al., 2009a,b). These studies were devoted to the assay of $\mathrm{Cu}(\mathrm{II}), \mathrm{Pb}(\mathrm{II}), \mathrm{Cd}(\mathrm{II})$, and $\mathrm{Hg}(\mathrm{II})$ (Figure 6). In the first two ones, the selectivity of the modified electrode has been tuned by varying the accumulation time and the pre-structuration of the polymer. The film thickness was also proved to influence the selectivity. However, the electrode was insensitive to $\mathrm{Cd}(\mathrm{II})$ whatever the conditions adopted. To overcome this problem, Heitzmann et al. have chosen an imprinted polymer strategy: the polymer was electrodeposited in the presence of $\mathrm{Cd}(\mathrm{II})$ ions which were then removed from the metallopolymer film (Heitzmann et al., 2007). The resulting functionalized electrode was thus able to detect $\mathrm{Cd}$ (II) as well as the other three metal cations. By introducing 4 pyrrole fragments on the same EDTA skeleton instead of only two in the former studies, an enhanced stability and a better controlled dimensionality was conferred to the polymer, thus making the sensor response independent on the film thickness (Buica et al., 2009a). The global complexing capability of the polymer was also greatly improved by the presence of 2 amine and 4 amide coordinating groups per monomer unit. The second group of polymers developed by the group of Moutet is based on poly(pyrrole-malonic acid) (Heitzmann et al., 2005; Pereira et al., 2011). Here, the analyte complexation occurred with the anionic form of malonic acid, which is known to easily coordinate various metal ions. This sensor was also tested with $\mathrm{Cu}(\mathrm{II}), \mathrm{Pb}(\mathrm{II}), \mathrm{Cd}(\mathrm{II})$, and $\mathrm{Hg}$ (II). It allowed LODs around $10^{-10} \mathrm{M}$ to be reached for each metal cation, and exhibited good stability since the same current response was obtained for 2 assays at a 3 weeks interval using the same electrode stored without any particular precaution.

Another kind of polymer based on styrene units gave rise to one report by Moutet (Rivas et al., 2006). Styrene was copolymerized with acetamide acrylic acid or itaconic acid. These latter are hydrophilic whereas styrene is hydrophobic,

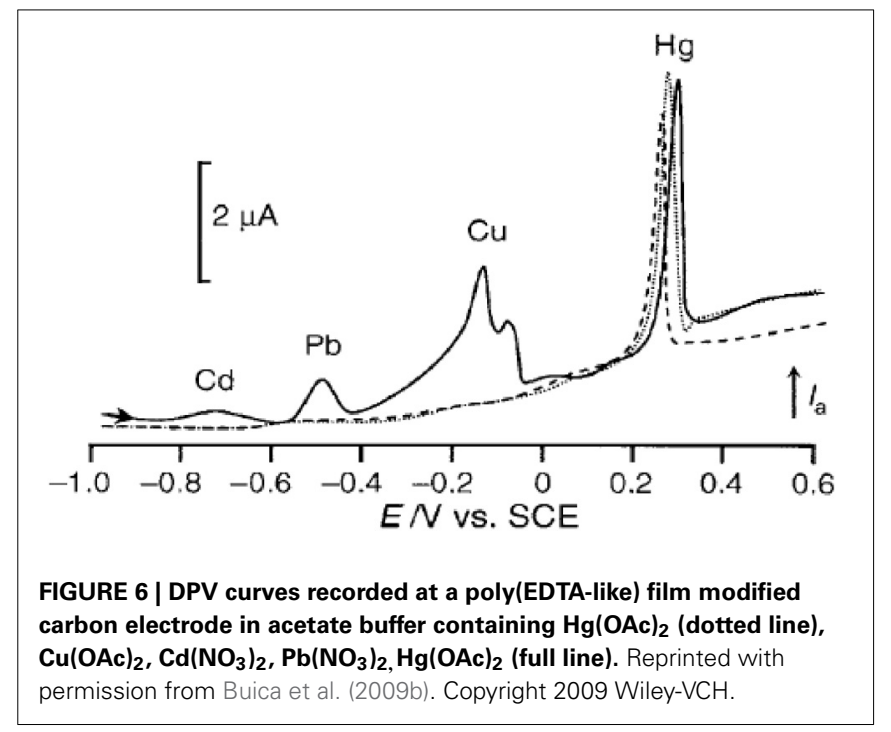

thus providing interesting mixed properties to the resulting copolymers. The incorporated carboxilate groups were used for the accumulation and detection of $\mathrm{Pb}^{2+}$ but the system exhibited poor performances since the response was linear only in the narrow range from $10^{-5}$ to $10^{-3} \mathrm{M}$.

Bessbousse et al. proposed a more sophisticated system based on a nanoporous $\beta$-poly(vinylidene fluoride) ( $\beta$-PVDF) membrane (Bessbousse et al., 2011). The nanopores were further functionalized by track-etched poly(acrylic acid) (PAA), and thin porous $\mathrm{Au}$ films were sputtered on each side of the membrane. This very sophisticated electrode has been proved to detect $\mathrm{Pb}^{2+}$ but no very clear analytical results were provided.

Polythiophene also gave rise to one report (Zejli et al., 2007). The polymer was electrodeposited on a Pt electrode by cyclic voltammety and used to detect $\mathrm{Ag}(\mathrm{I})$ by DPASV taking advantage of the inductive effect of the C-S dipole of thiophene units. However, the linear range was found to be very narrow, from 0.65 to $9.3 \mu \mathrm{M}$.

A contribution from the group of Noguet has also to be noticed (Yasri et al., 2011). In this original work, a graphite electrode coated by a 3,4-poly(ethylenedioxythiophene):poly(styrene sulfonate) [PEDOT:poly(styrene sulfonate)] copolymer was used to detect $\mathrm{Pb}^{2+}$ by chronoamperometry at $-0.35 \mathrm{~V}$. The linearity range was from 2 to $100 \mathrm{nM}$ and the LOD was $0.19 \mathrm{nM}$ for $30 \mathrm{~s}$ accumulation at $-0.65 \mathrm{~V}$. The system exhibited good stability since only a slight decrease was noticed after 11 days. It was also successfully tested for the determination of $\mathrm{Pb}^{2+}$ in different vegetables extracts.

In order to improve the detection limit the group of Chevalet exploited the high resolution power of a multi-pulse electroanalytical method, namely multiple square wave voltammetry (MSWV) (Fatouros et al., 1986; Krulic et al., 1990). MSWV is based on the superimposition of several pairs of opposite pulses of constant amplitude on each step of a staircase waveform. However MSWV differs from previously described DAPV by the electrode response: instead of the double cathodic and anodic 
current recorded in the latter case, MSWV response results in the integration of the successive currents. The MSWV-DD (DD for double differential) technique was used in combination with a Nafion-coated electrode for the determination of trace species like methylmercury (Moretto et al., 1999) and Fe (Ugo et al., 2001). The perfluorinated cation exchanger Nafion was used to preconcentrate the analyte and was simply deposited on a GC disk by droplet evaporation. The detection capabilities of this polymer-coated electrode combined to the sensitive MSWV-DD method allowed a calculated LOD down to $45 \mathrm{pM}$ to be reached for methylmercury (Moretto et al., 1999).

\section{Nano-scaled materials}

During the last two decades, nano-scaled materials have aroused a great interest with respect to analytical applications due to their specific physico-chemical properties (Murray, 2008). Improvements resulting from those nanomaterials for electroanalysis are manifold: enhanced diffusion of electroactive species, higher effective surface area of nanoparticles (NPs), electrocatalytic and conductive properties, improved selectivity and higher signal-to-noise ratio. With respect to trace metal analysis, gold nanoparticles (AuNPs) are the most commonly used material (Lin et al., 2011; Liu et al., 2011). They can be obtained either by chemical or electrochemical ways.

The French contribution to this topic is very recent, and the corresponding works all considered the structuration of the nanoparticle-based modified electrode to be a key feature with respect to analytical performances.
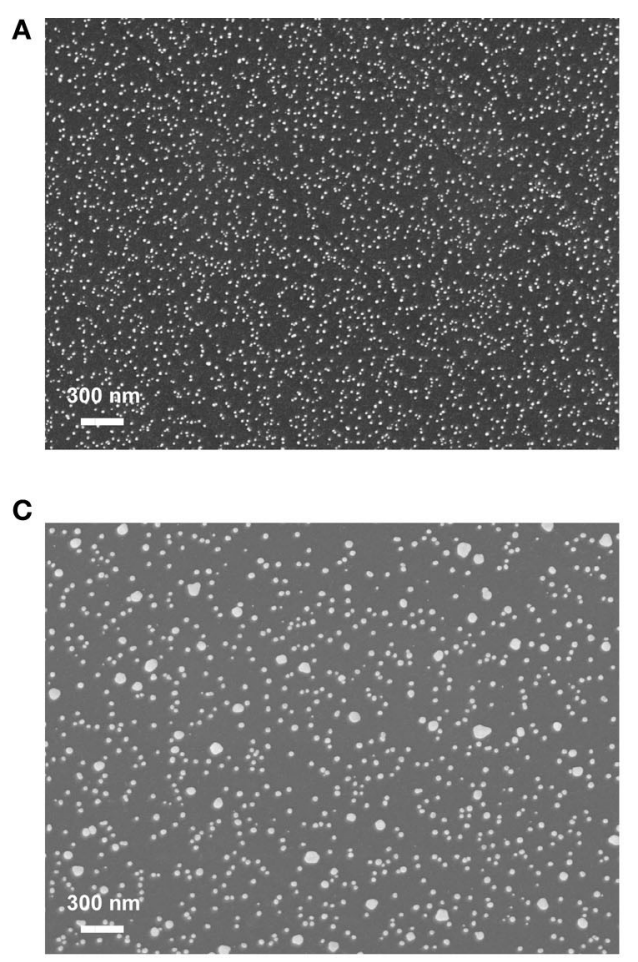

FIGURE 7 | AuNPs electrodeposited onto GC from a $0.25 \mathrm{mM} \mathrm{HAuCl}_{4}$ solution using: (A) chronoamperometry; (B) potentiostatic double pulse; (C) cyclic voltammetry. (D) SWASV response and calibration curve obtained
Ottakam Thotiyl et al. designed a multilayer arrangement of citrate-capped AuNPs immobilized by a thiol group onto a $\mathrm{Au}$ electrode for the detection of As(III) (Ottakam Thotiyl et al., 2012). The anionic AuNPs were deposited layer-by-layer alternatively with cationic polyelectrolyte to afford a layered nanocomposite film. As(III) was detected by its electrocatalytic oxidation using DPV without any accumulation step, and a LOD of $0.48 \mu \mathrm{M}$ was reported. This study evidenced a strong correlation between the amperometric response and the number of layers of the nanocomposite film.

Our group has developed a $\mathrm{Hg}(\mathrm{II})$ sensor based on GC electrode functionalized by electrodeposited AuNPs and has studied the influence of the electrodeposition method on the analytical performances (Hezard et al., 2012a,b). Namely, cyclic voltammetry, chronoamperometry and potentiostatic double-pulse were used. It was shown that both the electrodeposition mode and the charge used for the Au precursor reduction had a dramatic influence on the size and density of AuNPs (Figure 7). These latter two parameters were strongly correlated to the analytical performances: the best results were obtained for dense deposits of small NPs (Hezard et al., 2012b). By using a 5 min accumulation time and SWASV, a LOD of $0.4 \mathrm{nM}$ was reached.

An important development in the frame of nano-scaled materials concerns single (SWCNTs) or multi-walled carbon nanotubes (MWCNTs) since their discovery in 1991 (Ijima, 1991). Their unique structure offers very interesting properties such as high specific surface area, high chemical stability, good electrical conductivity and adsorption capacity, which give rise to
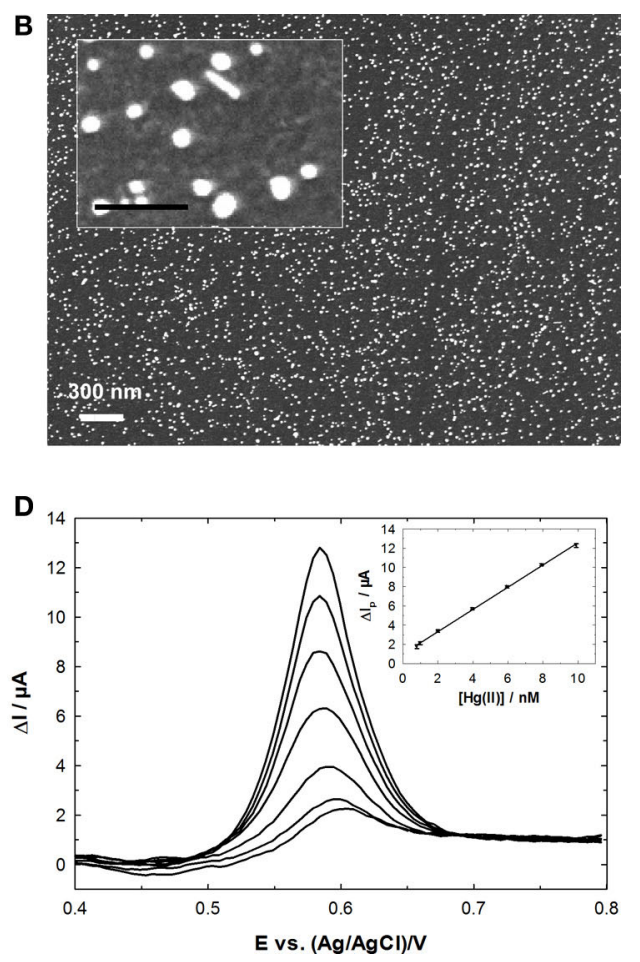

in the $\mathrm{Hg}(\mathrm{II})$ concentration range $0.8-9.9 \mathrm{nM}$ using electrode (A). Adapted from our own results published in Hezard et al. (2012b), Copyright 2012 Elsevier. 
wide applications in electronics, composite materials, energy storage, and of course sensors (Fam et al., 2011). With respect to this latter domain the association of various CNT functionalization procedures, including organic (polymers, proteins...) or inorganic (metal nanoparticles, metal oxides...) modifiers and several transducing modes allowed the elaboration and development of chemical, gas, humidity, biomedical or environmental sensors which have been the subject of several reviews (Jacobs et al., 2010; Vashist et al., 2011; Gao et al., 2012). Extensive international researches have been made to assay heavy metals by using unmodified (Yue et al., 2012) or CNTs modified either with cysteine (Morton et al., 2009), thiacalixarene (Wang et al., 2012), Sb nanoparticles (Ashrafi et al., 2014) or with imprinted polymeric nanobeads (Rajabi et al., 2013), most of the time associated with ASV. They allowed $\mathrm{Pb}, \mathrm{Hg}, \mathrm{Cu}, \mathrm{Cd}$, or $\mathrm{Zn}$ to be detected down to $3 \mathrm{nM}$ and in linear concentration ranges up to $7 \mu \mathrm{M}$. Surprisingly, to the best of our knowledge, no French research team has exploited CNTs for heavy metals detection yet. Interest has mainly focused on micro and supercapacitors (Ghimbeu et al., 2011), batteries (Carn et al., 2013) and energy storage devices (Sathiya et al., 2011) or biofuel cells (Both Engel et al., 2013; De Poulpiquet et al., 2013). Concerning sensors works essentially dealt with gaz sensors (Bondavalli, 2010) and above all enzymatic (Singh et al., 2013), RNA (Tran et al., 2013) and DNA (Zhang et al., 2011)-based electrochemical biosensors.

\section{Biosensors}

In general terms, a biosensor is defined as an analytical tool associating a bioactive compound (mono- or multi-enzyme system, antibody, microorganism) which can specifically recognize species of interest and a transducing element (Frew and Hill, 1987). Thus, it may be viewed as a particular kind of CME in which the modifier is a biological element. Enzymes are known as good modifiers with respect to heavy metals since these latter often strongly inhibit enzymatic reactions (Dennison and Turner, 1995).

The group of Chovelon reported several works about conductometric biosensors based on Chlorella vulgaris, a microalgae the cell walls of which bear enzymes such as alkaline phosphatases and esterases (Chouteau et al., 2004, 2005). In both papers, the microorganism was immobilized onto interdigitated Pt electrodes using bovine serum albumin and glutaraldehyde as a crosslinker. In the first work, $\mathrm{Cd}^{2+}$ was detected as low as $8.9 \mathrm{nM}$ but at least one hour was needed to obtain such a result. The second study (Chouteau et al., 2005) provided several improvements since both $\mathrm{Cd}^{2+}$ and $\mathrm{Zn}^{2+}$ were detected with a $89 \mathrm{nM}$ and $0.15 \mu \mathrm{M}$ LOD, respectively, but with a significantly lower exposure time (ca. $30 \mathrm{~min}$ ). It has to be noticed that bioassays were found to reach a similar LOD to the biosensor but only after $4 \mathrm{~h}$ exposure time, illustrating the wise enzyme immobilization strategy used. Finally, an originality of this latter work was that the biosensor was also capable to detect pesticides, taking advantage of the fact that esterases were selectively inhibited by these organic compounds whereas alkaline phosphatases were not affected.

Tekaya et al. have also reported a conductometric biosensor based on alkaline phosphatase from the cyanobacterium Arthrospira platensis (Tekaya et al., 2013) deposited on the ceramic part of interdigitated Au electrodes. In this case, inhibition measurements were performed after $24 \mathrm{~h}$ incubation, allowing LOD down to $10^{-20} \mathrm{M}$ to be reached for both analytical targets, namely $\mathrm{Cd}^{2+}$ and $\mathrm{Hg}^{2+}$. Despite this very appreciable LOD, no information was provided about sensor lifetime. This is mainly due to the fact that the authors considered their study as a proof of concept aiming at providing a global response to the presence of heavy metals.

A last conductometric biosensor was reported 2 years ago by Soldatkin et al. (2012). This sensor consisted in a three-enzyme system prepared by mixing invertase, mutarotase and glucose oxidase with bovine serum albumin. Although a bit complicated, the sensor exhibited good sensitivities toward $\mathrm{Hg}^{2+}$ and $\mathrm{Ag}^{+}$ without experiencing any interference from organic compounds. After a relatively short incubation time (ca. 10-20 min), the LOD were found to be 25 and $100 \mathrm{nM}$ for $\mathrm{Hg}^{2+}$ and $\mathrm{Ag}^{+}$, respectively. It has to be noticed that this biosensor was very selective since $\mathrm{Cd}^{2+}, \mathrm{Zn}^{2+}, \mathrm{Ni}^{2+}, \mathrm{Pb}^{2+}, \mathrm{Cu}^{2+}$, and $\mathrm{Co}^{2+}$ did not affect the enzymes activities. Interestingly, the authors have investigated a reactivation procedure: dipping the biosensor into EDTA or cysteine solution for $45 \mathrm{~min}$ allowed a significant reactivation of the enzymes together with the identification of the inhibitor metal, since EDTA reactivated $\mathrm{Ag}^{+}$inhibition only whereas cysteine was selective to $\mathrm{Hg}^{2+}$ inhibition.

The group of Cosnier proposed an amperometric sensor toward $\mathrm{Hg}$ (II) based on the same three enzymes which were entrapped in a clay matrix deposited on $\mathrm{Pt}$ electrode (Mohammadi et al., 2005). The electrochemical response was provided by the oxidation of the enzymatically produced hydrogen peroxide. After $20 \mathrm{~min}$ incubation, $\mathrm{Hg}$ (II) was detected in the range $10 \mathrm{nM}$ to $1 \mu \mathrm{M}$. It has to be noticed that several $\mathrm{Hg}$ species have been tested, such as methylmercury or phenylmercury, all of them leading to invertase inhibition. Depending of the analytical target, the biosensor recovery by using cysteine was more or less effective, but never complete. The system was quite selective to $\mathrm{Hg}(\mathrm{II})$ since all metal cations tested induced no interferences except $\mathrm{Ag}^{+}$.

Finally, the group of Burstein has reported 20 years ago a bi-enzymatic system coupled to an oxygen sensor (a Clark electrode) which offered an original solution to the enzyme recovery issue (Gayet et al., 1993). In this work, several enzyme combinations were tested but the most interesting one was that involving L-lactate oxidase and L-lactate dehydrogenase. Actually, the former enzyme was immobilized on the membrane of the oxygen sensor whereas the latter one remained in solution. Since only L-lactate dehydrogenase was affected by the presence of heavy metal cations, the sensor regeneration simply consisted in a renewal of the solution containing this very cheap enzyme. Unfortunately, the interest of this system was limited due to the relatively poor LOD obtained for the different analytical targets.

\section{THE PARTICULAR ISSUE OF TRACE METAL SPECIATION}

In addition to the monitoring of total heavy metals concentrations in the environment, speciation analysis provides very useful complementary informations. However speciation analysis often implies the determination of very low concentrations of minor species, typically in the range of $\mathrm{nM}$ to $\mathrm{pM}$ or even lower. Hence 
electrochemistry and especially anodic stripping techniques are particularly well adapted to such kind of analysis.

For instance, Bourgeault et al. studied dissolved $\mathrm{Cu}$ speciation and bioavailability in freshwaters by using DPASV, diffusive gradient in thin films and ISE, and compared their results to those obtained by modeling (Bourgeault et al., 2013). It was found that $\mathrm{Cu}$ accumulation in aquatic mosses was better correlated to the weakly complexed $\mathrm{Cu}$ species measured using DPASV than to free $\mathrm{Cu}$ concentration measured using an ISE, thus highlighting the contribution of electrochemical techniques to speciation studies.

In a close approach combining DPASV and conductometry, Terbouche et al. examined the complexation of $\mathrm{Zn}$ (II) and Cd(II) by new humic acids from Algeria, these latter class of natural polymers being known to have an influence on heavy metals biogeochemical cycle and bioavailability (Terbouche et al., 2011). Based on the strong complexing capacities evidenced in this work, the authors suggested their humic acids to be used for metal uptake.

A last speciation study combining electrochemical techniques was provided very recently by Rotureau (2014). Here the already discussed "AGNES" technique was used for the determination of free metal in solution while SCP at scanned deposition potential (SSCP) allowed dynamic speciation information to be reached. This latter technique consists in performing classical SCP with varying deposition potentials, and then plotting the transition time as a function of the deposition potential (van Leeuven and Town, 2002). Rotureau's work dealt with $\mathrm{Cd}$ and $\mathrm{Pb}$ speciation dynamics in clay minerals, and it was shown that the interaction of Cd with clays may be described as a chemically homogeneous, labile system over a wide $\mathrm{pH}$ range whereas strong $\mathrm{pH}$ effects were evidenced in the case of $\mathrm{Pb}$.

SSCP has also been used by Parat et al. to study Cd speciation parameters in the presence of several ligands, namely nitrilotriacetic acid (NTA) and 2,6-pyridinedicarboxylic acid (PDCA) (Parat et al., 2011b). By using a Hg film SPE and a $60 \mathrm{~s}$ deposition time, a LOD of $2.2 \mathrm{nM}$ was reached and some information upon speciation extracted. In particular, it was demonstrated that Cd-NTA complex is less labile than Cd-PDCA.

It has to be noticed that classical SCP has been used by the group of Riso for the determination of $\mathrm{Se}(\mathrm{IV})$ and total Se in seawater on a HgFE (Riso et al., 2004). However in this case, speciation information was reached by tuning the experimental parameters of water pretreatment, the electrochemical ones remaining nearly the same. Thus, $\mathrm{Se}$ (IV) concentration was determined by performing SCP on untreated water, whereas total Se was reached by analyzing UV-digested water.

Among all anodic stripping methods, pseudopolarography is particularly well-suited to provide useful information on metal speciation in model solutions and in natural water. This electrochemical technique allows thermodynamic and kinetic properties of the different forms of metal ions to be reached. The current-potential curves obtained, called pseudopolarograms, depict the influence of the metal deposition potential on the peak height, the peak potential or the half-peak width of the subsequent anodic voltammogram. The shifts in peak potentials as well as the changes in the slope of the curve indicate a modification in the reaction kinetics or reversibility. These evolutions make it possible to discriminate between different fractions of metals, including free or labile species and electroinactive metal complexes, and to detect the presence of complexing ligands at low concentration. Compared to classical linear or pulsed voltammetry, pseudopolarography allows the speciation of trace metals at natural concentration level (generally less than $\mathrm{nM}$ ). Pizeta et al. have taken benefit of this properties to detect $\mathrm{Pb}(\mathrm{II})$ in sediment and interstitial water with an iridium solid microelectrode covered by a thin mercury film (Pizeta et al., 2005). The electrode sensitivity varied between 4 and $20 \mathrm{nA} / \mu \mathrm{M}$ and its LOD was about $30 \mathrm{nM}$. The amperometric response was repeatable enough, avoiding memory effect and electrode surface blocking. Particularly the results highlighted the existence of strong complexes in sediment and in non-filtered interstitial water with high $\mathrm{pH}$. More recently this procedure was successfully applied for the study of the interactions of natural (NOM) or dissolved (DOM) organic matter with $\mathrm{Cu}$ and $\mathrm{Zn}$ (Louis et al., 2008; Nicolau et al., 2008) in seawater sample. The unpolluted marine water containing DOM about $1 \mathrm{mg} \mathrm{L}^{-1}$, measurements were possible in the latter case after concentrating DOM in large water volumes by nanofiltration and reverse-osmosis. Anyway the results gave comprehensive elements on the role of marine DOM in metals speciation: the dependence of pseudopolarograms with $\mathrm{pH}$ clearly indicated the differences of DOM sites for $\mathrm{Cu}$ and $\mathrm{Zn}$ complexation regarding their stability and acidity constants. The main drawback is the time-consuming of the method which requires a set of anodic stripping voltammograms to be recorded for each pseudopolarogram.

To end this section dedicated to heavy metal speciation, let's talk about some works which are certainly not the most original ones in terms of electroanalytical method, but present particularly interesting automated systems. Zaouak et al. recently developed a system for Cd semicontinuous monitoring which allowed the determination of total and bioavailable Cd (Zaouak et al., 2010a,b). The analyses were performed using a $\mathrm{Hg}$ film deposited on a SPE, this latter electrode being integrated in a fully-automated device allowing all the operations needed for a complete set of measurements. Thus, a measurement cell, a storage cell and a plating cell for the electrode renewal were comprised in the whole device, together with a hydraulic conveyor which allowed the three-electrode system to move from one cell to another. This automated device was tested on tap water by recording measurements every $160 \mathrm{~min}$ for $18.5 \mathrm{~h}$ and exhibited a LOD of $1.78 \mathrm{nM}$. Total and bioavailable $\mathrm{Cd}$ were obtained by adjusting the $\mathrm{pH}$ value of the treated water.

Another example of automated electroanalytical device was reported by Hezard et al. for $\mathrm{Fe}(\mathrm{III})$ and $\mathrm{Fe}(\mathrm{II})$ quantification in acid mining drainage water (Hezard et al., 2009). In this particular case, the redox species were concentrated enough to allow direct determination using an unmodified Pt electrode. Moreover, the presence of sulfide anion $\mathrm{S}^{2-}$ in acid drainage water induced an important negative shift in potential for $\mathrm{O}_{2}$ reduction, resulting in a well-separated reduction wave for $\mathrm{Fe}(\mathrm{III})$. Thus, both $\mathrm{Fe}(\mathrm{III})$ and $\mathrm{Fe}$ (II) were determined using a single potential scan without deaerating the solution. An originality of this work was that 
both sample renewal and hydrodynamic control were achieved by a fluidic system based on gravity instead of a pump.

\section{CONCLUSION}

From an historical point of view, the unique properties of the conventional mercury electrode have been at the origin of considerable efforts with respect to electrochemical methods devoted to heavy metals detection in water. Nowadays the great experience in polarographic techniques coupled with the improvements in data processing for the monitoring of pulsed potential sequences is still encouraging several groups to exploit the background on this electrode. Nevertheless recent trends have focused on mercuryfree electrode since this metal will be totally prohibited in the next few years (European Directive 2008/105/EC). Depending on whether the goal is heavy metal pollution detection in industrial waste or drinking water analysis, detection limits in the $\mu \mathrm{M}$ or nM have to be reached, respectively. In the former case ISEs are well-suited due to the simplicity of the potentiometric measurement and the good understanding of the sensing mechanism. On the other hand the detection of trace metals requires more sensitive methods. In that way CMEs represent a good alternative toward expensive, inconvenient analytical methods developed in laboratory. The combination of amperometric transduction with the specificity induced by the modifier makes it possible to propose reagentless sensors exhibiting high sensitivity and good selectivity. Furthermore the large range of available strategies for surface modification allows multielectrodes or micro array sensors to be designed for simultaneous multicomponent analysis in complex media. Finally a new generation of analytical devices called "micro total analysis system" ( $\mu$ TAS) is being developed for the "on line" monitoring of real samples. These devices integrate not only the sensing element but also some complementary actuators (pumps, valves, microfluidic channels) to obtain an all-integrated automatic monitoring system which includes a calibration procedure. A few prototypes have been recently proposed by using microtechnology manufacturing and semi-conductor processing (Jothimuthu et al., 2011; Jung et al., 2011) but are still at the emerging state. Still a good challenge for French research community!!

\section{REFERENCES}

Agra-Gutierrez, C., and Compton, R. G. (1998). Sono-adsorptive stripping voltammetry: Its application to the analysis of metals and organic compounds in aqueous media. Electroanalysis 10, 603-612. doi: 10.1002/(SICI)15214109(199807)10:9\%3C603::AID-ELAN603\%3E3.3.CO;2-D

Aragay, G., and Merkoçi, A. (2012). Nanomaterials application in electrochemical detection of heavy metals. Electrochim. Acta 84, 49-61. doi: 10.1016/j.electacta.2012.04.044

Arrigan, D. W. M. (1994). Voltammetric determination of trace metals and organics after accumulation at modified electrodes. Analyst 119, 1953-1966. doi: 10.1039/an9941901953

Ashrafi, A. M., Cerovac, S., Mudric, S., Guzsvany, V., Husakova, L., Urbanova, I., et al. (2014). Antimony nanoparticle-multiwalled carbon nanotubes composite immobilized at carbon paste electrode for determination of trace heavy metals. Sens. Actuators B 191, 320-325. doi: 10.1016/j.snb.2013.08.087

Bard, A. J., and Faulkner, L. R. (2001). Electrochemical Methods. Fundamentals and Applications. New York, NY: John Wiley and Sons.

Bessbousse, H., Nandhakumar, I., Decker, M., Barsbay, M., Cuscito, O., Lairez, D., et al. (2011). Functionalized nanoporous track-etched b-PVDF membrane electrodes for lead(II) determination by square wave anodic stripping voltammetry. Anal. Methods 3, 1351-1359. doi: 10.1039/clay05038a
Betelu, S., Parat, C., Petrucciani, N., Castetbon, A., Authier, L., and Potin-Gautier, M. (2007). Semicontinuous monitoring of cadmium and lead with a screenprinted sensor modified by a membrane. Electroanalysis 19, 399-402. doi: 10.1002/elan.200603722

Bobacka, J., Ivaska, A., and Lewenstam, A. (2008). Potentiometric ion sensors. Chem. Rev. 108, 329-351. doi: 10.1021/cr068100w

Bondavalli, P. (2010). Carbon nanotubes based transistors composed of singlewalled carbon nanotubes mats as gas sensors: a review. C. R. Phys. 11, 389-396. doi: 10.1016/j.crhy.2010.06.002

Both Engel, A., Cherifi, A., Tingry, S., Cronu, D., Peigney, A., and Laurent, C. (2013). Enhanced performance of electrospun carbon fibers modified with carbon nanotubes: promising electrodes for enzymatic biofuel cells. Nanotechnology 24, 245402-245409. doi: 10.1088/0957-4484/24/24/245402

Bourgeault, A., Ciffroy, P., Garnier, C., Cossu-Leguille, C., Masfaraud, J.-F., Charlatchka, R., et al. (2013). Speciation and bioavailability of dissolved copper in different freshwaters: comparison of modelling, biological and chemical responses in aquatic mosses and gammarids. Sci. Total Environ. 452-453, 68-77. doi: 10.1016/j.scitotenv.2013.01.097

Buica, G. O., Bucher, C., Moutet, J.-C., Royal, G., Saint-Aman, E., and Ungureanu, E. M. (2009a). Voltammetric sensing of mercury and copper cations at poly(EDTA-like) film modified electrode. Electroanalysis 21, 77-86. doi: 10.1002/elan.200804386

Buica, G. O., Ungureanu, E. M., Bucher, C., Moutet, J.-C., and Saint-Aman, E. (2009b). Poly(pyrrole-EDTA like) modified electrodes for mercury ions electroanalysis. J. Optoelectron. Adv. M. 11, 1152-1159.

Cali, C., Foix, D., Taillades, G., Siebert, E., Gonbeau, D., Pradel, A., et al. (2002). Copper(II) selective electrode based on chalcogenide materials: study of the membrane/solution interface with electrochemical impedance spectroscopy and X-ray photoelectron spectroscopy. Mater. Sci. Eng. C 21, 3-8. doi: 10.1016/S0928-4931(02)00053-X

Callender, E. (2004). Heavy metals in the environment-historical trends. Treatise Geochem. 9, 67-105. doi: 10.1016/B0-08-043751-6/09161-1

Carn, F., Morcrette, M., Desport, B., and Backov, R. (2013). Lithium-ion battery electrode prepared by confining carbon nanotubes $/ \mathrm{V}_{2} \mathrm{O}_{5}$ nanoribbons suspension in model air-liquid foams. Solid States Sci. 17, 134-139. doi: 10.1016/j.solidstatesciences.2012.10.019

Caroli, S., Forte, G., Iamiceli, A. L., and Galoppi, B. (1999). Determination of essential and potentially toxic trace elements in honey by inductively coupled plasmabased techniques. Talanta 50, 327-336. doi: 10.1016/S0039-9140(99)00025-9

Chouteau, C., Dzyadevych, S., Chovelon, J. M., and Durrieu, C. (2004). Development of novel conductometric biosensors based on immobilised whole cell chlorella vulgaris microalgae. Biosens. Bioelectron. 19, 1089-1096. doi: 10.1016/j.bios.2003.10.012

Chouteau, C., Dzyadevych, S., Durrieu, C., and Chovelon, J. M. (2005). A bienzymatic whole cell conductometric biosensor for heavy metal ions and pesticides detection in water samples. Biosens. Bioelectron. 21, 273-281. doi: 10.1016/j.bios.2004.09.032

Commissariat général au développement durable. (2011). Bilan de présence des micropolluants dans les milieux aquatiques continentaux 2007-2009. Obs. Stat. 54, (Octobre 2011).

Commissariat général au développement durable. (2012). Chiffres clés de l'environnement, Edition 2012. Obs. Stat. (Septembre 2012).

Cox, J. A., Tess, M. E., and Cummings, T. E. (1996). Electroanalytical methods based on modified electrodes: a review of recent advances. Rev. Anal. Chem. 15, 173-223. doi: 10.1515/REVAC.1996.15.3.173

Crini, G. (2005). Recent developments in polysaccharide-based materials used as adsorbents in wastewater treatment. Prog. Polym. Sci. 30, 38-70. doi: 10.1016/j.progpolymsci.2004.11.002

Cugnet, C., Zaouak, O., Rene, A., Pecheyran, C., Potin-Gautier, M., and Authier, L. (2009). A novel microelectrode array combining screen-printing and femtosecond laser ablation technologies: development, characterization and application to cadmium detection. Sens. Actuators B 143, 158-163. doi: 10.1016/j.snb.2009.07.059

Dennison, M. J., and Turner, A. P. F. (1995). Biosensors for environmental monitoring. Biotech. Adv. 13, 1-12. doi: 10.1016/0734-9750(94)00020-D

De Poulpiquet, A., Ciaccafava, A., Szot, K., Pillain, B., Infossi, P., Guiral, M., et al. (2013). Exploring properties of a hyperthermophilic membrane-bound hydrogenase at carbon nanotube modified electrodes for a powerful $\mathrm{H}_{2} / \mathrm{O}_{2}$ biofuel cell. Electroanalysis 25, 685-695. doi: 10.1002/elan.201200405 
Dernane, C., Zazoua, A., Kazane, I., and Jaffrezic-Renault, N. (2013). Cadmiumsensitive electrode based on tetracetone derivatives of p-tert-butylcalix[8] arene. Mat. Sci. Eng. C 33, 3638-3643. doi: 10.1016/j.msec.2013.04.049

El Kaoutit, M. (2012). "Application of conducting polymers in electroanalysis," in Aspects on Fundaments and Applications of Conducting Polymers. ed A. J. Motheo (Rijeka: InTech), 43-66.

El Tall, O., Jaffrezic-Renault, N., Sigaud, M., and Vittori, O. (2007). Anodic stripping voltammetry of heavy metals at nanocrystalline boron-doped diamond electrode. Electroanalysis 19, 1152-1159. doi: 10.1002/elan.200603834

Essi, M. M.-M. M., and Pradel, A. (2011a). Metal-sulphide ISE for copper(II) detection. Chalcogenide Lett. 8, 301-308.

Essi, M. M.-M. M., and Pradel, A. (2011b). Micro-electrode for copper ion detection in solution. Chalcogenide Lett. 8, 15-23.

Etienne, M., Bessiere, J., and Walcarius, A. (2001). Voltammetric detection of $\mathrm{Cu}(\mathrm{II})$ at a CPE containing an organically modified silica. Sens. Actuators B 76, 531-538. doi: 10.1016/S0925-4005(01)00614-1

Etienne, M., Cortot, J., and Walcarius, A. (2007). Preconcentration electroanalysis at surfactant-templated thiol-functionalized silica thin films. Electroanalysis 19, 129-138. doi: 10.1002/elan.200603677

European Directive 2000/60/EC. Community action in the field of water policy. OJ L327/01.

European Directive 2008/105/EC. Directive on Environmental quality standards. OJ L348 annex II.

Fam, D. W. H., Palaniappan, A., Tok, A. I. Y., Liedberg, B., and Moochhala, S. M. (2011). A review on technological aspects influencing commercialization of carbon nanotube sensors. Sens. Actuators B 157, 1-7. doi: 10.1016/j.snb.2011.03.040

Fatouros, N., Simonin J.P., Chevalet, J., and Reeves, R. M. (1986). Theory of multiple square wave voltammetries. J. Electroanal. Chem. 213, 1-16. doi: 10.1016/0022-0728(86)80592-7

Feier, B., Floner, D., Cristea, C., Bodoki, E., Sandulescu, R., and Geneste, F. (2012). Flow electrochemical analyses of zinc by stripping voltammetry on graphite felt electrode. Talanta 98, 152-156. doi: 10.1016/j.talanta.2012.06.063

Feldmann, J., Salaun, P., and Lombi, E. (2009). Critical review perspective: elemental speciation analysis methods in environmental chemistry - moving towards methodological integration. Environ. Chem. 6, 275-289. doi: 10.1071/EN09018

Frew, J. E., and Hill, H. A. O. (1987). Electrochemical biosensors. Anal. Chem. 59, 933A-944A. doi: 10.1021/ac00142a720

Friedman, J. R., Ashton, W. B., and Rapoport, R. D. (1993). A review of the global emissions, transport and effects of heavy metals in the environment. Report PNL-SA-22394; Order No. DE93016817. Richland, WA.

Ganesan, V., and Walcarius, A. (2008). Ion exchange and ion exchange voltammetry with functionalized mesoporous silica materials. Mater. Sci. Eng. B 149, 123-132. doi: 10.1016/j.mseb.2007.11.022

Gao, C., Guo, Z., Liu, J.-H., and Huang, X.-J. (2012). The new age of carbon nanotubes: an updated review of functionalized carbon nanotubes in electrochemical sensors. Nanoscale 4, 1948-1963. doi: 10.1039/c2nr11757f

Gayet, J. C., Haouz, A., Geloso-Meyer, A., and Burstein, C. (1993). Detection of heavy metal salts with biosensors built with an oxygen electrode coupled to various immobilized oxidases and dehydrogenases. Biosens. Bioelectron. 8, 177-183. doi: 10.1016/0956-5663(93)85030-R

Ghimbeu, C. M., Raymundo-Pinero, E., Fioux, P., Beguin, F., and Vix-Guterl, C. (2011). Vanadium nitride/carbon nanotube nanocompsites as electrodes for supercapacitors. J. Mater. Chem. 21, 13268-13275. doi: 10.1039/cljm11014d

Gilmartin, M. A. T., and Hart, J. P. (1995). Sensing with chemically and biologically modified carbon electrodes. A review. Analyst 120, 1029-1045. doi: 10.1039/an9952001029

Goncalves, M. D. L. S., Sigg, L., and Stumm, W. (1985). Voltammetric methods for distinguishing between dissolved and particulate metal ion concentrations in the presence of hydrous oxides. a case study on lead(II). Environ. Sci. Technol. 19, 141-146. doi: 10.1021/es00132a005

Goubert-Renaudin, S., Etienne, M., Rousselin, Y., Denat, F., Lebeau, B., and Walcarius, A. (2009a). Cyclam-functionalized silica-modified electrodes for selective determination of $\mathrm{Cu}(\mathrm{II})$. Electroanalysis 21, 280-289. doi: 10.1002/elan.200804378

Goubert-Renaudin, S., Moreau, M., Despas, C., Meyer, M., Denat, F., Lebeau, B., et al. (2009b). Voltammetric detection of lead(II) using amide-cyclamfunctionalized silica-modified carbon paste electrodes. Electroanalysis 21, 1731-1742. doi: 10.1002/elan.200904661
Guo, Z., Feng, F., Hou, Y., and Jaffrezic-Renault, N. (2005). Quantitative determination of zinc in milkvetch by anodic stripping voltammetry with bismuth film electrodes. Talanta 65, 1052-1055. doi: 10.1016/j.talanta.2004.08.060

Hamilton, J. W., Kaltreider, R. C., Bajenova, O. V., Ihnat, M. A., McCaffrey, J., Turpie, B. W., et al. (1998). Molecular basis for effects of carcinogenic heavy metals on inducible gene expression. Environ. Health Persp. Supp. 106, 1005-1015. doi: 10.1289/ehp.98106s41005

Heitzmann, M., Basaez, L., Brovelli, F., Bucher, C., Limosin, D., Pereira, E., et al. (2005). Voltammetric sensing of trace metals at a poly(pyrrole-malonic acid) film modified carbon electrode. Electroanalysis 17, 1970-1976. doi: 10.1002/elan.200503325

Heitzmann, M., Bucher, C., Moutet, J.-C., Pereira, E., Rivas, B. L., Royal, G., et al. (2007). Complexation of poly(pyrrole-EDTA like) film modified electrodes: application to metal cations electroanalysis. Electrochim. Acta 52, 3082-3087. doi: 10.1016/j.electacta.2006.09.041

Heyrovsky, J. (1922). Elektrolysa se rtufovou kapkoyou kathodou. Chem. Listy 16, $256-264$.

Heyrovsky, J. (1960). Trends in polarography. Science 132, 123-130. doi: 10.1126/science.132.3420.123

Hezard, T., Durand, G., Rakib, M., Viers, Ph., Roy, S., Guigues, N., et al. (2009). Metal on-line voltammetric analyzer for on-site monitoring of iron speciation in acid mine drainage waters: development and characterization. Electroanalysis 21, 1401-1410. doi: 10.1002/elan.200804538

Hezard, T., Fajerwerg, K., Evrard, D., Colliere, V., Behra, P., and Gros, P. (2012a). Gold nanoparticles electrodeposited on glassy carbon using cyclic voltammetry: application to $\mathrm{Hg}(\mathrm{II})$ trace determination. J. Electroanal. Chem. 664, 46-52. doi: 10.1016/j.jelechem.2011.10.014

Hezard, T., Fajerwerg, K., Evrard, D., Colliere, V., Behra, P., and Gros, P. (2012b). Influence of the gold nanoparticles electrodeposition method on $\mathrm{Hg}$ (II) trace electrochemical detection. Electrochim. Acta 73, 15-22. doi: 10.1016/j.electacta.2011.10.101

Ijima, S. (1991). Helical microtubules of graphitic carbon. Nature 354, 56-58. doi: $10.1038 / 354056 \mathrm{a} 0$

Jacobs, C. B., Peairs, M. J., and Venton, B. J. (2010). Carbon nanotube based electrochemical sensors for biomolecules. Anal. Chim. Acta 662, 105-127. doi: 10.1016/j.aca.2010.01.009

Järup, L. (2003). Hazards of heavy metal contamination. Br. Med. Bull. 68, 167-182. doi: $10.1093 / \mathrm{bmb} / \mathrm{ldg} 032$

Jothimuthu, P., Wilson, R. A., Herren, J., Haynes, E. N., Heineman, W. R., and Papautsky, I. (2011). Lab-on-a-chip sensor for detection of highly electronegative heavy metals by anodic stripping voltammetry. Biomed. Microdevices 13, 695-703. doi: 10.1007/s10544-011-9539-1

Jung, W., Jang, A., Bishop, P. L., and Ahn, C. H. (2011). A polymer lab chip sensor with microfabricated planar silver electrode for continuous and on-site heavy metal measurement. Sens. Actuators B 155, 145-153. doi: 10.1016/j.snb.2010.11.039

Kenawy, I. M. M., Hafez, M. A. H., Akl, M. A., and Lashein, R. R. (2000). Determination by AAS of some trace heavy metal ions in some natural and biological samples after their preconcentration using newly chemically modified chloromethylated polystyrene-PAN ion-exchanger. Anal. Sci. 16, 493-500. doi: 10.2116/analsci.16.493

Khadro, B., Sikora, A., Loir, A.-S., Errachid, A., Garrelie, F., Donnet, C., et al. (2011). Electrochemical performances of B doped and undoped diamond-like carbon (DLC) films deposited by femtosecond pulsed laser ablation for heavy metal detection using square wave anodic stripping voltammetric (SWASV) technique. Sens. Actuators B 155, 120-125. doi: 10.1016/j.snb.2010.11.034

Khadro, B., Vittori, O., and Jaffrezic-Renault, N. (2009). A new differential pulse anodic stripping voltammetry miniaturized sensor system for detection of nickel and mercury in waters. Sensor Lett. 7, 829-832. doi: 10.1166/sl.2009.1157

Kolthoff, I. M. (1979). Application of macrocyclic compounds in chemical analysis. Anal. Chem. 51, 1R-22R. doi: 10.1021/ac50041a001

Kot, A., and Namiesńik, J. (2000). The role of speciation in analytical chemistry. Trends Anal. Chem. 19, 69-79. doi: 10.1016/S0165-9936(99)00195-8

Krulic, D., Fatouros, N., and Chevalet, J. (1990). Multiple square wave voltammetry: experimental verification of the theory. J. Electroanal. Chem. 287, 215-227. doi: 10.1016/0022-0728(90)80003-O

Le, T. S., Da Costa, P., Huguet, P., Sistat, P., Pichot, F., Silva, F., et al. (2012). Upstream microelectrodialysis for heavy metals detection on boron doped diamond. J. Electroanal. Chem. 670, 50-55. doi: 10.1016/j.jelechem.2012.02.015 
Legeai, S., Bois, S., and Vittori, O. (2006). A copper bismuth film electrode for adsorptive cathodic stripping analysis of trace nickel using square wave voltammetry. J. Electroanal. Chem. 591, 93-98. doi: 10.1016/j.jelechem. 2006.03.054

Legeai, S., Soropogui, K., Cretinon, M., Vittori, O., Oliveira, A. H. D., Barbier, F., et al. (2005). Economic bismuth-film microsensor for anodic stripping analysis of trace heavy metals using differential pulse voltammetry. Anal. Bioanal. Chem. 383, 839-847. doi: 10.1007/s00216-005-0083-9

Legeai, S., and Vittori, O. (2006). A Cu/Nafion/Bi electrode for on-site monitoring of trace heavy metals in natural waters using anodic stripping voltammetry: an alternative to mercury-based electrodes. Anal. Chim. Acta 560, 184-190. doi: 10.1016/j.aca.2005.12.010

Li, X., Wang, Y., Yang, X., Chen, J., Fu, H., and Cheng, T. (2012). Conducting polymers in environmental analysis. Trends Anal. Chem. 39, 163-179. doi: 10.1016/j.trac.2012.06.003

Lin, Y.-W., Huang, C.-C., and Chang, H.-T. (2011). Gold nanoparticle probes for the detection of mercury, lead and copper ions. Analyst 136, 863-871. doi: 10.1039/c0an00652a

Lindqvist, O. (1995). Environmental impact of mercury and other heavy metals. J. Power Sources 57, 3-7. doi: 10.1016/0378-7753(95)02229-5

Liu, Y., Su, G., Zhang, B., Jiang, G., and Yan, B. (2011). Nanoparticle-based strategies for detection and remediation of environmental pollutants. Analyst 136, 872-877. doi: 10.1039/c0an00905a

Louis, Y., Cmuk, P., Omanovic, D., Garnier, C., Lenoble, V., Mounier, S., et al. (2008). Speciation of trace metals in natural waters: the influence of an adsorbed layer of natural organic matter (NOM) on voltammetric behavior of copper. Anal. Chim. Acta 606, 37-44. doi: 10.1016/j.aca.2007.11.011

Lu, D., Belle, J. L., Ninivin, C. L., Mabic, S., and Dimitrakopoulos, T. (2010). In situ electrochemical detection of trace metal vapors at bismuth doped carbon screen printed electrodes. J. Electroanal. Chem. 642, 157-159. doi: 10.1016/j.jelechem.2010.02.022

Luther III, G. W., and Ferdelman, T. G. (1993). Voltammetric characterization of iron(II) sulfide complexes in laboratory solutions and in marine waters and porewaters. Environ. Sci. Technol. 27, 1154-1163. doi: 10.1021/es00043a015

Magnier, A., Billon, G., Louis, Y., Baeyens, W., and Elskens, M. (2011). On the liability of dissolved $\mathrm{Cu}, \mathrm{Pb}$ and $\mathrm{Zn}$ in freshwater: optimization and application to the Deûle (France). Talanta 86, 91-98. doi: 10.1016/j.talanta.2011.08.010

Martin, S., and Griswold, W. (2009). Human health effects of heavy metals. Environ. Sci. Technol. Br. Cit. 15, 1-6.

McCreery, R. L. (2008). Advanced carbon electrode materials for molecular electrochemistry. Chem. Rev. 108, 2646-2687. doi: 10.1021/cr068076m

Mear, F., Essi, M., Pradel, A., Ribes, M., Sistat, P., and Huguet, P. (2005). "Detection of heavy ions in polluted waters: use of chalcogenide sensors and pre-concentration module," in Proceedings of the International Conference on Solid Waste Technology and Management 21st (Philadelphia, PA), 582-591.

Mhatre, G. N. (1995). Heavy metal pollution in the biosphere and bioindicators and biomonitoring of heavy metals. Encycl. Environ. Control Technol. 8, 427-454.

Mohammadi, H., Amine, A., Cosnier, S., and Mousty, C. (2005). Mercuryenzyme inhibition assays with an amperometric sucrose biosensor based on a trienzymatic-clay matrix. Anal. Chim. Acta 543, 143-149. doi: 10.1016/j.aca.2005.04.014

Moretto, L. M., Ugo, P., Lacasse, R., Champagne, G. Y., and Chevalet, J. (1999). Determination of methylmercury at Nafion coated electrodes by single and multiple pulse voltammetric techniques. J. Electroanal. Chem. 467, 193-202. doi: 10.1016/S0022-0728(98)00449-5

Morton, J., Havens, N., Mugweru, A., and Wanekaya, A. K. (2009). Detection of trace heavy metals ions using carbon nanotube-modified electrodes. Electroanalysis 21, 1597-1603. doi: 10.1002/elan.200904588

Munteanu, G., Munteanu, S., and Wipf, D. O. (2009). Rapid determination of zeptomole quantities of $\mathrm{Pb}^{2+}$ with the mercury monolayer carbon fiber electrode. J. Electroanal. Chem. 632, 177-183. doi: 10.1016/j.jelechem.2009. 04.014

Murray, R. W. (2008). Nanoelectrochemistry: metal nanoparticles, nanoelectrodes, and nanopores. Chem. Rev. 108, 2688-2720. doi: 10.1021/cr068077e

Murray, R. W., Ewing, A. G., and Durst, R. A. (1987). Chemically modified electrodes. Molecular design for electroanalysis. Anal. Chem. 59, 379A-390A.

Musarrat, J., Zaidi, A., Khan, M. S., Siddiqui, M. A., and Al-Khedhairy, A. A. (2011). Genotoxicity assessment of heavy metal-contaminated soils. Environ. Pollut. 20, 323-342. doi: 10.1007/978-94-007-1914-9_14
Nagajyoti, P. C., Lee, K. D., and Sreekanth, T. V. M. (2010). Heavy metals, occurrence and toxicity for plants: a review. Environ. Chem. Lett. 8, 199-216. doi: 10.1007/s10311-010-0297-8

Nasraoui, R., Floner, D., and Geneste, F. (2009). Analytical performances of a flow electrochemical sensor for preconcentration and stripping voltammetry of metal ions. J. Electroanal. Chem. 629, 30-34. doi: 10.1016/j.jelechem.2009.01.024

Nasraoui, R., Floner, D., and Geneste, F. (2010a). Improvement in performance of a flow electrochemical sensor by using carbamoyl-arms polyazamacrocycle for the preconcentration of lead ions onto the electrode. Electrochem. Commun. 12, 98-100. doi: 10.1016/j.elecom.2009.10.045

Nasraoui, R., Floner, D., Paul-Roth, C., and Geneste, F. (2010b). Flow electroanalytical system based on cyclam-modified graphite felt electrodes for lead detection. J. Electroanal. Chem. 638, 9-14. doi: 10.1016/j.jelechem. 2009.10.028

Navratilova, Z., and Kula, P. (2003). Clay modified electrodes: present applications and prospects. Electroanalysis 15, 837-846. doi: 10.1002/elan.200390103

Nicolau, R., Louis, Y., Omanovic, D., Garnier, C., Mounier, S., and Pizeta, I. (2008). Study of interactions of concentrated marine dissolved organic matter with copper and zinc by pseudopolarography. Anal. Chim. Acta 618, 35-42. doi: 10.1016/j.aca.2008.04.038

Ottakam Thotiyl, M. M., Basit, H., Sanchez, J. A., Goyer, C., Coche-Guerente, L., Dumy, P., et al. (2012). Multilayer assemblies of polyelectrolyte-gold nanoparticles for the electrocatalytic oxidation and detection of arsenic(III). J. Colloid Interface Sci. 383, 130-139. doi: 10.1016/j.jcis.2012.06.033

Parat, C., Authier, L., Aguilar, D., Companys, E., Puy, J., Galceran, J., et al. (2011a). Direct determination of free metal concentration by implementing stripping chronopotentiometry as the second stage of AGNES. Analyst 136, 4337-4343. doi: $10.1039 / \mathrm{clan} 15481 \mathrm{~h}$

Parat, C., Authier, L., Betelu, S., Petrucciani, N., and Potin-Gautier, M. (2007). Determination of labile cadmium using a screen-printed electrode modified by a microwell. Electroanalysis 19, 403-406. doi: 10.1002/elan.200603734

Parat, C., Betelu, S., Authier, L., and Potin-Gautier, M. (2006). Determination of labile trace metals with screen-printed electrode modified by a crown-ether based membrane. Anal. Chim. Acta 573-574, 14-19. doi: 10.1016/j.aca.2006.04.081

Parat, C., Schneider, A., Castetbon, A., and Potin-Gautier, M. (2011b). Determination of trace metal speciation parameters by using screen-printed electrodes in stripping chronopotentiometry without deaerating. Anal. Chim. Acta 688, 156-162. doi: 10.1016/j.aca.2010.12.034

Pereira, E., Rivas, B. L., Heitzmann, M., Moutet, J.-C., Bucher, C., Royal, G., et al. (2011). Complexing polymer films in the preparation of modified electrodes for detection of metal ions. Macromol. Symp. 304, 115-125. doi: 10.1002/masy.201150616

Pizeta, I., Billon, G., Omanovic, D., Cuculic, V., Garnier, C., and Fischer, J.-C. (2005). Pseudopolarography of lead(II) in sediment ad in interstitial water measured with a solid microelectrode. Anal. Chim. Acta 551, 65-72. doi: 10.1016/j.aca.2005.07.009

Pohl, P. (2009). Determination of metal content in honey by atomic absorption and emission spectrometries. Trends Anal. Chem. 28, 117-128. doi: 10.1016/j.trac.2008.09.015

Prabhakar, S., Singh, A. K., and Pooni, D. S. (2012). Effect of environmental pollution on animal and human health: a review. Ind. J. Anim. Sci. 82, 244-255.

Rajabi, H. R., Roushani, M., and Shamsipur, M. (2013). Development of a highly selective voltammetric sensor for nanomolar detection of mercury ions using glassy carbon electrode modified with a novel ion imprinted polymeric nanobeads and multi-wall carbon nanotubes. J. Electroanal. Chem. 693, 16-22. doi: 10.1016/j.jelechem.2013.01.003

Riso, R. D., Le Corre, P., and Chaumery, C. J. (1997). Rapid and simultaneous analysis of trace metals $(\mathrm{Cu}, \mathrm{Pb}, \mathrm{Cd})$ in seawater by potentiometric stripping analysis. Anal. Chim. Acta 351, 83-89. doi: 10.1016/S0003-2670(97) 00352-8

Riso, R. D., Waeles, M., Garbarino, S., and Le Corre, P. (2004). Measurement of total selenium and selenium(IV) in seawater by stripping chronopotentiometry. Anal. Bioanal. Chem. 379, 1113-1119. doi: 10.1007/s00216-004-2677-z

Riso, R. D., Waeles, M., Pernet-Coudrier, B., and Le Corre, P. (2006). Determination of dissolved iron(III) in estuarine and coastal waters by adsorptive stripping chronopotentiometry (SCP). Anal. Bioanal. Chem. 385, 76-82. doi: 10.1007/s00216-006-0393-6 
Rivas, B. L., Pooley, S. A., Brovelli, F., Pereira, E., Basaez, L., Puentes, J., et al. (2006). Synthesis and properties of styrene copolymers. Preparation of filmmodified electrodes to detect $\mathrm{Pb}^{2+}$ ions. J. Appl. Polym. Sci. 100, 2380-2385. doi: 10.1002/app. 23090

Rotureau, E. (2014). Analysis of metal speciation dynamics in clay minerals dispersion by stripping chronopotentiometry techniques. Colloids Surf. A 441, 291-297. doi: 10.1016/j.colsurfa.2013.09.006

Rouis, A., Echabaane, M., Sakly, N., Dumazet-Bonnamour, I., and Ben Ouada, H. (2013). Electrochemical analysis of a PPV derivative thin film doped with betaketoimine calix [4] arene in the dark and under illumination for the detection of $\mathrm{Hg}^{2+}$ ions. Synthetic Met. 164, 78-87. doi: 10.1016/j.synthmet.2013.01.005

Roy, S. P. (2010). Overview of heavy metals and aquatic environment with notes on their recovery. Ecoscan 4, 235-240.

Sanchez, A., and Walcarius, A. (2010). Surfactant-templated sol-gel silica thin films bearing 5-mercapto-1-methyl-tetrazole on carbon electrode for $\mathrm{Hg}$ (II) detection. Electrochim. Acta 55, 4201-4207. doi: 10.1016/j.electacta.2010. 02.016

Sathiya, M., Prakash, A. S., Ramesha, K., Tarascon, J.-M., and Shukla, A. K. (2011). $\mathrm{V}_{2} \mathrm{O}_{5}$-anchored carbon nanotubes for enhanced electrochemical energy storage. J. Am. Chem. Soc. 133, 16291-16299. doi: 10.1021/ja207285b

Sayen, S., Gerardin, C., Rodehuser, L., and Walcarius, A. (2003). Electrochemical detection of copper(II) at an electrode modified by a carnosine-silica hybrid material. Electroanalysis 15, 422-430. doi: 10.1002/elan.200390049

Sbartai, A., Namour, P., Errachid, A., Krejci, J., Sejnohova, R., Renaud, L., et al. (2012). Electrochemical boron-doped diamond film microcells micromachined with femtosecond laser: application to the determination of water framework directive metals. Anal. Chem. 84, 4805-4811. doi: 10.1021/ac3003598

Seck, S. M., Charvet, S., Fall, M., Baudrin, E., Lejeune, M., and Benlahsen, M. (2012). Detection of cadmium and copper cations using amorphous nitrogenated carbon thin film electrodes. Electroanalysis 24, 1839-1846. doi: 10.1002/elan.201200219

Silva, E. L., dos Santos Roldan, P., and Giné, M. F. (2009). Simultaneous preconcentration of copper, zinc, cadmium, and nickel in water samples by cloud point extraction using 4-(2-pyridylazo)-resorcinol and their determination by inductively coupled plasma optic emission spectrometry. J. Hazard. Mater. 171, 1133-1138. doi: 10.1016/j.jhazmat.2009.06.127

Singh, M., Holzinger, M., Biloivan, O., and Cosnier, S. (2013). 3D-nanostructured scaffold electrodes based on single-walled carbon nanotubes and nanodiamonds for high performance biosensors. Carbon 61, 349-356. doi: 10.1016/j.carbon.2013.05.015

Sladkov, V., David, F., and Fourest, B. (2003). Copper-mercury film electrode for cathodic stripping voltammetric determination of Se(IV). Anal. Bioanal. Chem. 375, 300-305. doi: 10.1007/s00216-002-1672-5

Soldatkin, O. O., Kucherenko, I. S., Pyeshkova, V. M., Kukla, A. L., JaffrezicRenault, N., El'skaya, A. V., et al. (2012). Novel conductometric biosensor based on three-enzyme system for selective determination of heavy metal ions. Bioelectrochemistry 83, 25-30. doi: 10.1016/j.bioelechem.2011.08.001

Suib, S. L. (2013). Some grand challenges in environmental chemistry. FCHEM 1, 1-2. doi: 10.3389/fchem.2013.00001

Superville, P.-J., Louis, Y., Billon, G., Prygiel, J., Omanovic, D., and Pizeta, I. (2011). An adaptable automatic trace metal monitoring system for on line measuring in natural waters. Talanta 87, 85-92. doi: 10.1016/j.talanta.2011.09.045

Svancara, I., Prior, C., Hocevar, S. B., and Wang, J. (2010). A decade with bismuth-based electrodes in electroanalysis. Electroanalysis 22, 1405-1420. doi: 10.1002/elan.200970017

Tanguy, V., Waeles, M., Vandenhecke, J., and Riso, R. D. (2010). Determination of ultra-trace $\mathrm{Sb}$ (III) in seawater by stripping chronopotentiometry (SCP) with a mercury film electrode in the presence of copper. Talanta 81, 614-620. doi: 10.1016/j.talanta.2009.12.050

Tchinda, A. J., Ngameni, E., Kenfack, I. T., and Walcarius, A. (2009). One-step preparation of thiol-functionalized porous clay heterostructures: application to $\mathrm{Hg}$ (II) binding and characterization of mass transport issues. Chem. Mater. 21, 4111-4121. doi: $10.1021 / \mathrm{cm} 8024022$

Tchinda, A. J., Ngameni, E., and Walcarius, A. (2007). Thiol-functionalized porous clay heterostructures (PCHs) deposited as thin films on carbon electrode: towards mercury(II) sensing. Sens. Actuators, B 121, 113-123. doi: 10.1016/j.snb.2006.09.005

Tekaya, N., Saiapina, O., Ben Ouada, H., Lagarde, F., Ben Ouada, H., and JaffrezicRenault, N. (2013). Ultra-sensitive conductometric detection of heavy metals based on inhibition of alkaline phosphatase activity from Arthrospira platensis. Bioelectrochemistry 90, 24-29. doi: 10.1016/j.bioelechem.2012.10.001

Templeton, D. M., Ariese, F., Cornelis, R., Danielsson, L.-G., Muntau, H., van Leeuven, H. P., et al. (2000). Guidelines for terms related to chemical speciation and fractionation of elements. Pure Appl. Chem. 72, 1453-1470. doi: 10.1351/pac200072081453

Terbouche, A., Djebbar, S., Benali-Baitich, O., and Hauchard, D. (2011). Complexation study of humic acids extracted from forest and sahara soils with zinc(II) and cadmium(II) by differential pulse anodic stripping voltammetry (DPASV) and conductimetric methods. Water Air Soil Pollut. 216, 679-691. doi: 10.1007/s11270-010-0562-2

Tonle, I. K., Letaief, S., Ngameni, E., Walcarius, A., and Detellier, C. (2011). Square wave voltammetric determination of lead(II) ions using a carbon paste electrode modified by a thiol-functionalized kaolinite. Electroanalysis 23, 245-252. doi: 10.1002/elan.201000467

Tonle, I. K., Ngameni, E., Njopwouo, D., Carteret, C., and Walcarius, A. (2003). Functionalization of natural smectite-type clays by grafting with organosilanes: physico-chemical characterization and application to mercury(II) uptake. Phys. Chem. Chem. Phys. 5, 4951-4961. doi: 10.1039/b308787e

Tonle, I. K., Ngameni, E., and Walcarius, A. (2004). From clay- to organoclayfilm modified electrodes: tuning charge selectivity in ion exchange voltammetry. Electrochim. Acta 49, 3435-3443. doi: 10.1016/j.electacta.2004.03.012

Tonle, I. K., Ngameni, E., and Walcarius, A. (2005). Preconcentration and voltammetric analysis of mercury(II) at a carbon paste electrode modified with natural smectite-type clays grafted with organic chelating groups. Sens. Actuators, B 110, 195-203. doi: 10.1016/j.snb.2005.01.027

Tran, H. V., Piro, B., Reisberg, S., Tran, L. D., Duc, H. T., and Pham, M. C. (2013). Label-free and reagentless electrochemical detection of microRNAs using a conducting polymer nanostructured by carbon nanotubes: application to prostate cancer biomarker miR-141. Biosens. Bioelectron. 49, 164-169. doi: 10.1016/j.bios.2013.05.007

Trojanowicz, M. (2003). Application of conducting polymers in chemical analysis. Mikrochim. Acta 143, 75-91. doi: 10.1007/s00604-003-0066-5

Ugo, P., Moretto, L. M., Rudello, D., Birriel, E., and Chevalet, J. (2001). Trace iron determination by cyclic and multiple square-wave voltammetry at nafion coated electrodes. application to pore-water analysis. Electroanalysis 13, 661-668. doi: 10.1002/1521-4109(200105)13:8/9<661::AID-ELAN661>3.0.CO;2-N

Urbanova, V., Bartos, M., Vytras, K., and Kuhn, A. (2010). Porous bismuth film electrodes for signal increase in anodic stripping voltammetry. Electroanalysis 22, 1524-1530. doi: 10.1002/elan.200970016

Vallee, B. L., and Ulmer, D. D. (1972). Biochemical effects of mercury, cadmium, and lead. Annu. Rev. Biochem. 41, 91-128. doi: 10.1146/annurev.bi.41.070172.000515

van Leeuven, H. P., and Town, R. M. (2002). Stripping chronopotentiometry at scanned deposition potential (SSCP). Part 1. Fundamental features. J. Electroanal. Chem. 536, 129-140. doi: 10.1016/S0022-0728(02)01212-3

Vashist, S. K., Zheng, D., Al-Rubeaan, K., Luong, J. H. T., and Sheu, F.-S. (2011). Advances in carbon nanotube based electrochemical sensors for bioanalytical applications. Biotechnol. Adv. 29, 169-188. doi: 10.1016/j.biotechadv.2010.10.002

Vieira, R. S., Oliveira, M. L. M., Guibal, E., Rodriguez-Castellon, E., and Beppu, M. M. (2011). Copper, mercury and chromium adsorption on natural and crosslinked chitosan films: an XPS investigation of mechanism. Colloids Surf. A 374, 108-114. doi: 10.1016/j.colsurfa.2010.11.022

Voccia, D., Laschi, S., Palchetti, I., Marrazza, G., and Mascini, M. (2012). A Hgfree sensor to control trace metal ionization used to treat pathogens in water distribution systems. Electroanalysis 24, 882-888. doi: 10.1002/elan.201100622

Walcarius, A. (1998). Analytical applications of silica-modified electrodes. a comprehensive review. Electroanalysis 10, 1217-1235.

Walcarius, A., and Bessiere, J. (1997). Silica-modified carbon paste electrode for copper determination in ammoniacal medium. Electroanalysis 9, 707-713. doi: 10.1002/elan.1140090910

Walcarius, A., Despas, C., and Bessiere, J. (1999a). Selective monitoring of Cu(II) species using a silica modified carbon paste electrode. Anal. Chim. Acta 385, 79-89. doi: 10.1016/S0003-2670(98)00403-6

Walcarius, A., Despas, C., Trens, P., Hudson, M. J., and Bessiere, J. (1998). Voltammetric in situ investigation of an MCM-41-modified carbon paste electrode. a new sensor. J. Electroanal. Chem. 453, 249-252. doi: 10.1016/S00220728(98)00203-4 
Walcarius, A., Devoy, J., and Bessiere, J. (2000). Silica-modified electrode for the selective detection of mercury. J. Solid State Electrochem. 4, 330-336. doi: $10.1007 / \mathrm{s} 100080000109$

Walcarius, A., Etienne, M., Sayen, S., and Lebeau, B. (2003). Grafted silicas in electroanalysis: amorphous versus ordered mesoporous materials. Electroanalysis 15, 414-421. doi: 10.1002/elan.200390048

Walcarius, A., Luthi, N., Blin, J.-L., Su, B.-L., and Lamberts, L. (1999b). Electrochemical evaluation of polysiloxane-immobilized amine ligands for the accumulation of copper(II) species. Electrochim. Acta 44, 4601-4610. doi: 10.1016/S0013-4686(99)00181-4

Walcarius, A., and Sibottier, E. (2005). Electrochemically-induced deposition of amine-functionalized silica films on gold electrodes and application to $\mathrm{Cu}$ (II) detection in (hydro)alcoholic medium. Electroanalysis 17, 1716-1726. doi: 10.1002/elan.200503300

Wang, J. (1989). "Voltammetry following nanoelectrolytic preconcentration," in Electroanalytical Chemistry, Vol. 16. ed Bard, A. J. (New York, NY: Marcel Dekker), 238-272.

Wang, J., Larson, D., Foster, N., Armalis, S., Lu, J., Rongrong, X., et al. (1995). Remote electrochemical sensor for trace metal contaminants. Anal. Chem. 67, 1481-1485. doi: 10.1021/ac00104a029

Wang, J., Lu, J., Hocevar, S. B., and Farias, P. A. M. (2000). Bismuth-coated carbon electrodes for anodic stripping voltammetry. Anal. Chem. 72, 3218-3222. doi: $10.1021 / \mathrm{ac} 000108 \mathrm{x}$

Wang, J., Lu, J., Hocevar, S. B., and Ogorevc, B. (2001). Bismuth-coated screenprinted electrodes for stripping voltammetric measurements of trace lead. Electroanalysis 13, 13-16. doi: 10.1002/1521-4109(200101)13:1\%3C13::AIDELAN13\%3E3.0.CO;2-F

Wang, L., Wang, X., Shi, G., Peng, C., and Ding, Y. (2012). Thiacalixarene covalently functionalized multiwalled carbon nanotubes as chemically modified electrode material for detection of ultratrace $\mathrm{Pb}^{2+}$ ions. Anal. Chem. 84, 10560-10567. doi: 10.1021/ac302747f

Yaftian, M. R., Parinejad, M., and Matt, D. (2007). A lead-selective membrane electrode based upon a phosphorylated hexahomotrioxacalix[3]arene. J. Chin. Chem. Soc. (Taipei) 54, 1535-1542.

Yaftian, M. R., Rayati, S., Emadi, D., and Matt, D. (2006). A coated wire-type lead(II) ion-selective electrode based on a phosphorylated calix[4] arene derivative. Anal. Sci. 22, 1075-1078. doi: 10.2116/analsci.22.1075

Yasri, N. G., Halabi, A. J., Istamboulie, G., and Noguer, T. (2011). Chronoamperometric determination of lead ions using PEDOT:PSS modified carbon electrodes. Talanta 85, 2528-2533. doi: 10.1016/j.talanta.2011. 08.013

Yue, W., Riehl, B. L., Pantelic, N., Schlueter, K. T., Johnson, J. M., Wilson, R. A., et al. (2012). Anodic stripping voltammetry of heavy metals on a metal catalyst free carbon nanotube electrode. Electroanalysis 24, 1039-1046. doi: 10.1002/elan.201200065

Zaouak, O., Authier, L., Cugnet, C., Castetbon, A., and Potin-Gautier, M. (2009). Bismuth-coated screen-printed microband electrodes for on-field labile cadmium determination. Electroanalysis 21, 689-695. doi: 10.1002/elan.200804465

Zaouak, O., Authier, L., Cugnet, C., Castetbon, A., and Potin-Gautier, M. (2010a). Electroanalytical device for cadmium speciation in waters. Part 1: development and characterization of a reliable screen-printed sensor. Electroanalysis 22, 1151-1158. doi: 10.1002/elan.200900474

Zaouak, O., Authier, L., Cugnet, C., Normandin, E., Champier, D., Rivaletto, M., et al. (2010b). Electroanalytical device for cadmium speciation in water. Part 2: automated system development and cadmium semicontinuous monitoring. Electroanalysis 22, 1159-1165. doi: 10.1002/elan.200900475

Zejli, H., Hidalgo-Hidalgo de Cisneros, J. L., Naranjo-Rodriguez, I., and Temsamani, K. R. (2007). Stripping voltammetry of silver ions at polythiophene-modified platinum electrodes. Talanta 71, 1594-1598. doi: 10.1016/j.talanta.2006.07.052

Zhang, Q. D., Piro, B., Noel, V., Reisberg, S., and Pham, M. C. (2011) Functionalization of single-walled carbon nanotubes for direct and selective electrochemical detection of DNA. Analyst 136, 1023-1028. doi: 10.1039/c0an00486c

Zlatev, R. K., Stoytcheva, M. S., Salas, B. V., Magnin, J.-P., and Ozil, P. (2006). Simultaneous determination of species by differential alternative pulses voltammetry. Electrochem. Commun. 8, 1699-1706. doi: 10.1016/j.elecom.2006. 07.041

Conflict of Interest Statement: The authors declare that the research was conducted in the absence of any commercial or financial relationships that could be construed as a potential conflict of interest.

Received: 24 January 2014; accepted: 01 April 2014; published online: 30 April 2014. Citation: Pujol L, Evrard D, Groenen-Serrano K, Freyssinier M, Ruffien-Cizsak A and Gros P (2014) Electrochemical sensors and devices for heavy metals assay in water: the French groups' contribution. Front. Chem. 2:19. doi: 10.3389/fchem.2014.00019

This article was submitted to Analytical Chemistry, a section of the journal Frontiers in Chemistry.

Copyright (C) 2014 Pujol, Evrard, Groenen-Serrano, Freyssinier, Ruffien-Cizsak and Gros. This is an open-access article distributed under the terms of the Creative Commons Attribution License (CC BY). The use, distribution or reproduction in other forums is permitted, provided the original author(s) or licensor are credited and that the original publication in this journal is cited, in accordance with accepted academic practice. No use, distribution or reproduction is permitted which does not comply with these terms. 